Projeto de sistema crítico para transmissão de vídeo em um link de comunicação para vants

\author{
Diego Leonardo Função
}



Data de Depósito:

Assinatura:

\title{
Projeto de sistema crítico para transmissão de vídeo em um link de comunicação para vants
}

\author{
Diego Leonardo Função
}

Orientador: Prof. Dr. Edson Moreira

Dissertação apresentada ao Instituto de Ciências Matemáticas e de Computação - ICMC-USP, como parte dos requisitos para obtenção do título de Mestre em Ciências - Ciências de Computação e Matemática Computacional. VERSAO REVISADA

USP - São Carlos

Agosto de 2012 
Ficha catalográfica elaborada pela Biblioteca Prof. Achille Bassi e Seção Técnica de Informática, ICMC/USP, com os dados fornecidos pelo(a) autor(a)

\begin{tabular}{|c|c|}
\hline \multirow[t]{3}{*}{ F979p } & $\begin{array}{l}\text { Função, Diego } \\
\text { Projeto de sistema crítico para transmissão de } \\
\text { vídeo em um link de comunicação para vants / Diego } \\
\text { Função; orientador Edson Moreira. -- São Carlos, } 2012 \text {. } \\
\quad 43 \text { p. }\end{array}$ \\
\hline & $\begin{array}{l}\text { Dissertação (Mestrado - Programa de Pós-Graduação en } \\
\text { Ciências de Computação e Matemática Computacional) -- } \\
\text { Instituto de Ciências Matemáticas e de Computação, } \\
\text { Universidade de São Paulo, } 2012 \text {. }\end{array}$ \\
\hline & $\begin{array}{l}\text { 1. OFDM. 2. Comunicação Digital. 3. VANT. } 4 . \\
\text { Antenas. 5. Wireless. I. Moreira, Edson, orient. II. } \\
\text { Título. }\end{array}$ \\
\hline
\end{tabular}


Agradeço a todos do grupo SOHAND, coordenado pelo prof. Edson, e à FAPESP pelo apoio dado ao projeto. 


\section{Sumário}

1 Introdução $\quad 3$

1.1 Motivação . . . . . . . . . . . . . . . . . . . . . . 3

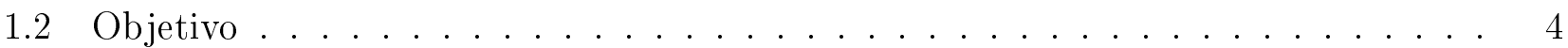

1.3 Organização do Trabalho . . . . . . . . . . . . . . . . . . . 5

2 Trabalhos Relacionados $\quad 6$

$\begin{array}{llr}3 & \text { Revisão Bibliográfica } & 7\end{array}$

$3.1 \quad$ Espectro Eletromagnético f . . . . . . . . . . . . . . . . . . . . . 8

3.2 Propagação de Ondas . . . . . . . . . . . . . . . . . . . . . . . 10

3.2.1 Fading de Larga Escala . . . . . . . . . . . . . . . . . . . 11

3.2.2 Fading de Pequena Escala . . . . . . . . . . . . . . 18

3.3 Técnicas de Diversidade na Transmissão . . . . . . . . . . . . . . . . . . . . . . . 19

3.4 Esquemas de Modulação . . . . . . . . . . . . . . . . . . . . . . . 22

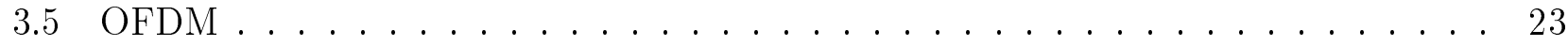

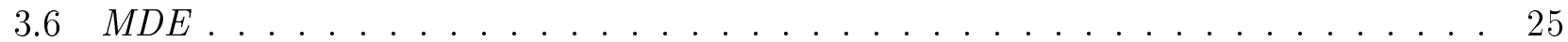

4 Solução Proposta $\quad 27$

4.1 Arquitetura da Solução . . . . . . . . . . . . . . . . . . 27

4.2 A ferramenta Matlab/Simulink . . . . . . . . . . . . . . . 28

4.3 Detalhes da Solução Adotada . . . . . . . . . . . . . . . . . . . . 29

4.3 .1 Data Source . . . . . . . . . . . . . . . . 30

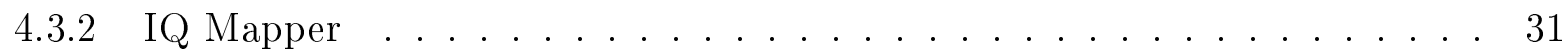


4.3 .3 OFDM Modulation Block .................... 31

4.3 .4 OFDM Demodulator . . . . . . . . . . . . . . . . . . 32

4.3 .5 IQ Demapper . . . . . . . . . . . . . . . . . . 32

4.4 Método proposto para Correção de Distorções na Resposta em Frequência do Canal 33

4.5 Simulação de Monte Carlo para encontrar Desempenho do Link . . . . . . . . . . 34

4.6 Link Budget . . . . . . . . . . . . . . . . . . . . . . 36

5 Conclusão e Trabalhos Futuros $\quad 39$

$\begin{array}{ll}\text { Referências Bibliográficas } & 41\end{array}$

Apêncice A - Trabalho Publicado em Evento Internacional 


\section{Lista de Figuras}

1 Espectro Eletromagnético . . . . . . . . . . . . . . . 8

2 Propagação de Ondas Terrestres $(f \leq 2 M H z)$ - Fonte: $[5]$ pg $421 \ldots \ldots$

3 Propagação de Ondas Ionosféricas $(2 M H z \leq f \leq 30 M H z)$ - Fonte: [5] pg 416 . . 11

4 Propagação de Ondas por Linha de Visada $(f \geq 30 M H z)$ - Fonte: [5] pg 420 . . . 11

5 Perdas por propagação de ondas no espaço-livre . . . . . . . . . . . . . . . 13

6 Efeito do Shadowing . . . . . . . . . . . . . . . . . . . . 14

7 Perdas no modelo de Hata . . . . . . . . . . . . . . . . . . 16

8 Antenas e Redundância Espacial . . . . . . . . . . . . . . . . . . . 21

9 Diagrama de Constelações para a Modulação QAM . . . . . . . . . . . . . 23

10 Subportadoras Entrelaçadas . . . . . . . . . . . . . . . . . . . 24

11 Prefixo Cíclico . . . . . . . . . . . . . . . . . 25

12 Picos do Sinal OFDM f . . . . . . . . . . . . . . . . 26

13 Diagrama de Blocos do Transceptor . . . . . . . . . . . . . . . . . . . 27

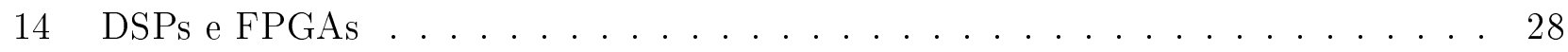

15 Modelo do Simulink gerado para o transmissor e receptor . . . . . . . . . . . . 30

16 Transformação de sinal no domínio da frequência para o domínio do tempo . . . . 32

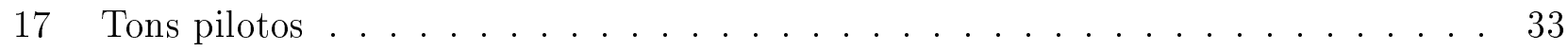

18 Bloco de Correção de Distorções no Canal através de Tons Pilotos . . . . . . . . 34

19 Bit Error Rate para canal Riciano . . . . . . . . . . . . . . . . 35

20 Bit Error Rate para canal Gaussiano . . . . . . . . . . . . . . . . . 36

21 Diâmetro da antena em função da frequência de operação . . . . . . . . . . . . 38 


\section{Lista de Tabelas}

1 Frequências disponíveis para comunicação digital por rádio sem autorização da

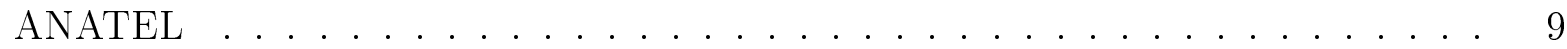

2 Configurações de Terreno para WiMax . . . . . . . . . . . . . . . 17

3 Parâmetros por tipo de terreno no modelo de perdas por propagação do padrão

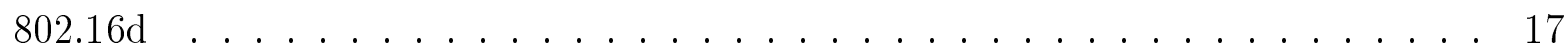

4 Power Delay Profile no modelo ITU-R para pedestres . . . . . . . . . . . . 18

5 Configurações de M-QAM . . . . . . . . . . . . . . . 30

6 Amplitude do Sinal dos Tons Pilotos . . . . . . . . . . . . . . . . . . 33 


\section{Resumo}

Este projeto tem como objetivo a especificação de um enlace de comunicação digital para veículos aéreos não tripulados. Os principais desafios presentes no meio de transmissão serão evidenciados, assim como o impacto acarretado no sistema de comunicação. O projeto foi dividido entre a parte analógica e digital. A parte analógica tratará dos requisitos de potência para o devido funcionamento do canal através do procedimento de link budget. O projeto da parte digital, por sua vez, empregará a técnica de transmissão OFDM. No presente trabalho foi sugerido um método de estimação do canal utilizando os tons pilotos. O desempenho desta abordagem será medido através de uma simulação de monte Carlo.

Palavras-Chave: VANTs, OFDM, Comunicação Digital 


\begin{abstract}
This project aims to design a digital data communication link for unmaned aerial vehicles. We will focus the main challenges and their impacts in the communication system. The project was divided in an analog and digital block. The analog block address the power requirements that make the system works by using a link budget procedure. The digital block will use the OFDM transmission technique. In this work we also suggest a channel estimation procedure via pilot tones. The performance of this approach will be measured by Monte Carlo Simulation.
\end{abstract}

Key-Words: UAVs, OFDM, Digital Communication 


\section{Introdução}

\subsection{Motivação}

Veículos aéreos não tripulados (VANTs) - em inglês Unmaned Aerial Vehicles (UAVs)) são caracterizados pela ausência de um operador a bordo[16]. Tipicamente, estes veículos são controlados de forma remota por um profissional, ou são capazes de executar uma missão previamente programada.

As missões dependem do tipo de aplicação. VANTs são utilizados intensamente em aplicações militares. Aplicações militares envolvem reconhecimento, vigilância, acompanhamento de inimigos e tropas. Todas estas aplicações se tornam vantangens estratégicas para o grupo que possui o VANT. O Departamento de Defesa dos EUA $(D o D)$ utiliza 5 tipos de VANTs [14].

- Global Hawk

- Air Forces Predator

- Navy and Marine Corps's Pioneer

- Army's Hunter

- Army's Shadow

O Global Hawk é utilizado para monitoramento e reconhecimento de terrenos. É equipado com câmeras de altíssima resolução e com sensores infravermelho. Segundo a força aérea americana este VANT pode carregar até $1300 \mathrm{Kg}$ e quase 8 toneladas de combustível[1]. Vale ressaltar que este VANT não possui nenhuma arma.

O Predator, ao contrário do Global Hawk, tem a função de combate, e por isso é equipado com vários tipos de armamentos.

O VANT Pioneer é utilizado pela marinha norte-americana para reconhecimento de terreno e do inimigo. Os outros dois, Hunter e Shadow são utilizados pelo exército, também, para reconhecimento e determinação dos melhores alvos.

Exemplos de aplicações civis são levantamento de ocupação urbana, monitoramento 
de tráfego, pecuária e agricultura. O projeto ARARA [25] desenvolvido no Instituto de Ciências Matemáticas e Computação (ICMC) utilizou VANTs para obtenção de imagens aéreas de lavouras, auxiliando o gerenciamento de plantações.

Todas as aplicações supracitadas necessitam de armazenamento e transmissão de informações coletadas. Um tipo de abordagem consiste em armazenar as informações coletadas e transmiti-las apenas quando o VANT voltar para a terra. A outra consiste em transmitir as informações continuamente no instante em que forem obtidas. Também é possível utilizar uma abordagem híbrida para transmissão de dados, no entanto, o presente trabalho trata o problema de transmissão contínua de informações.

O projeto ARARA coletava imagens aéreas e, apenas, quando o avião chegava ao solo era possível acessá-las. A grande vantagem em obter estas imagens em tempo real através de um link de comunicação é que a rota do avião pode ser alterada para focar em objetos, alvos ou areas que despertaram interesse durante a execução da missão.

\subsection{Objetivo}

O projeto tem como objetivo investigar os problemas mais relevantes que degradam a qualidade de enlaces de rádio e gerar as especificações necessárias para construção de um link de comunicação digital apropriado para comunicação entre VANTs e estações terrestres.

O trabalho se concentra em VANTs encarregados de fazer reconhecimento, vigilância e monitoramento de áreas, e, consequentemente, que precisam transmitir vídeo digital de alta resolução a longas distâncias (da ordem de dezenas de quilômetros). O enlace será capaz de transmitir vídeo compactado, como no padrão MPEG-4[20][26].

O problema será abordado por meio da técnica Model Driven Engineering (MDE), e o enlace simulado para determinação de seu comportamento para várias situações, representadas por diversos níveis de ruído e comportamento do canal. Também, serão discutidas as vantagens da técnica adotada $M D E$, e, porque a possível implementação 
do enlace em circuitos digitais e analógicos ocorreria de maneira eficiente.

Discutiremos algumas questões pertinentes a especificação de itens de hardware. Iremos no basear em características do canal, com base em modelos suficientemente adequados para instanciação do problema.

\subsection{Organização do Trabalho}

A Seção 1 possui uma breve introdução, juntamente, com o objetivo e motivação do trabalho. A Seção 2 detalha os trabalhos relacionados ao presente trabalho. A Seção 3 apresenta a revisão bibliográfica sobre comunicação wireless, modulação, modelos que descrevem o comportamento de canais de comunicação wireless e o método de transmissão OFDM. A Seção 4 detalha e justifica a abordagem e a solução adotada. A Seção 5 apresenta os resultados obtidos para as especificações de hardware analógico e digital do transceptor. 


\section{Trabalhos Relacionados}

Mahmood [14] implementou um sistema de comunicação Wireless em FPGAs utilizando a linguagem AHDL. O alcance do sistema projetado era de $100 \mathrm{~m}$ a $10 \mathrm{~km}$. O throughput variava de $64 \mathrm{kbps}$ até $744 \mathrm{kbps}$.

O trabalho de Mahmood concentrou-se em detalhar os blocos digitais implementados em FPGA. A transmisão de vídeo digital com alta qualidade não estava no escopo deste trabalho, visto que a taxa de transmissão atingida seria insuficiente realizar esta tarefa.

Zhan [30] abordou o problema de redes compostas por VANTs. Conforme os veículos alteravam sua posição, era necesário alterar a configuração de roteamento entre eles. Esta abordagem pode ser interpretada como computação ciente de contêxto[24] presente nos trabalhos de [10] e [15]. VANTs roteando sinais entre si podem formar redes do tipo Mesh [2][13].

O presente trabalho não explorará este tipo de arquitetura e se concentrará apenas no problema da comunicação entre uma estação terrestre e o VANT. As especificações foram obtidas para o funcionamento de um enlace até 100km e a largura de banda será suficiente para transmissão de vídeo digital em tempo real. 


\section{Revisão Bibliográfica}

Apesar de os sistemas de comunicação sem fio possuírem várias vantagens como mobilidade e facilidade de instalação, por outro lado, há limitações de desempenho em relação a estes sistemas. As limitações surgem em decorrência de vários fatores como limitações de utilização do espectro eletromagnético e, principalmente, devido ao comportamento incerto do canal, que no caso seria o ar.

A propagação de ondas pode ser afetada por fenômenos climáticos (temperatura, pressão atmosférica, poluição, etc.) ou impossibilidade de se manter uma linha de visada entre transmissor e receptor.

Além disso, os canais de transmissão via rádio têm suas características alteradas dinamicamente, ou seja, o canal se altera conforme o usuário se movimenta, e, também, quando o tempo passa. Por estas razões, é necessário um processo contínuo de estimação do canal de comunicação, diferentemente do que ocorre com os canais de comunicação com fio.

Ondas eletromagnéticas sofrem reflexões quando encontram obstáculos com dimensões muito maiores do que o seu comprimento de onda. Por outro lado, quando há objetos com superfícies irregulares ou com pequenas aberturas pode ocorrer o fenômeno da difração. Estes dois fenômenos podem melhorar ou prejudicar o desempenho do enlace de comunicação. Quando não há linha de visada, tipicamente em ambientes urbanos, a reflexão e a difração podem fazer com que o sinal chegue ao receptor, no entanto, haverá situações na qual a difração acarretará em perda de potência do sinal detectado e a reflexão causará interferências no sinal recebido devido ao efeito de multipercurso.

Outro fenômeno importante que ocorre nestes canais é o fading que é a variação na amplitude do sinal no tempo e na frequência[21]. Tipicamente, existem duas classificações para este fenômeno. Um é o fading de larga escala e o outro o de pequena escala. 


\subsection{Espectro Eletromagnético}

O espectro eletromagnético é composto por todas as faixas de frequência das ondas eletromagnéticas. A divisão das faixas de acordo com sua utilização está ilustrada na Figura 1.

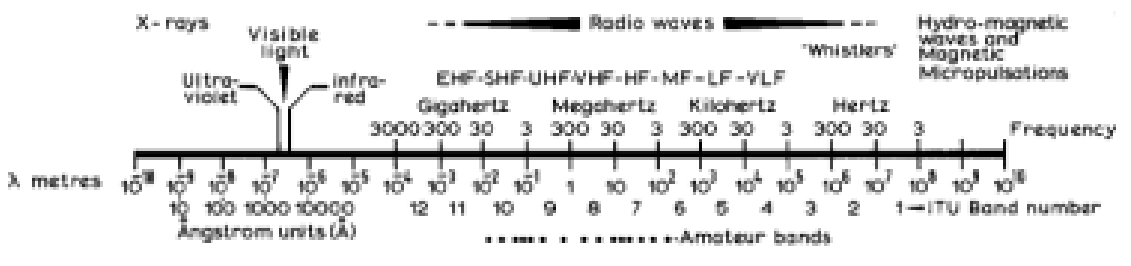

Figura 1: Espectro Eletromagnético

A ANATEL (Agência Nacional de Telecomunicações), criada em 1997, é a autarquia encarregada de administrar o espectro de radiofrequências e promover o desenvolvimento das telecomunicações no Brasil. Radiofrequência, de acordo com esta agência, é a faixa do espectro eletromagnético entre $9 \mathrm{Khz}$ e $300 \mathrm{Ghz}$.

O gerenciamento do espectro eletromagnético consiste na alocação, supervisão e na definição de regras para utilização destas ondas. Por exemplo, cabe à Anatel normatizar os níveis máximos de exposição dos seres humanos a campos eletromagnéticos, assim como definir quais tipos de serviços de comunicação podem utilizar certas frequências.

A ANATEL disponibiliza algumas faixas de frequência, descritas na tabela 1, para comunicação digital por rádio sem a necessidade de autorização, desde que utilizem a técnica de espalhamento espectral. A resolução $\mathrm{N}^{o} 365$, de 10 de maio de 2004, da ANATEL define esta técnica da seguinte maneira:

Espalhamento Espectral: tecnologia na qual a energia média do sinal transmitido é espalhada sobre uma largura de faixa muito maior do que a largura de faixa que contém a informação. Os sistemas empregando tal tecnologia compensam o uso de uma maior largura de faixa de transmissão com uma menor densidade espectral de potência e uma melhora na rejeição aos sinais interferentes de outros sistemas 
operando na mesma faixa de frequências.

Além desta característica, o sinal modulado de um sistema de comunicação por espalhamento espectral se assemelha a um sinal aleatório e sem correlação com os dados originais.

\begin{tabular}{|c|c||c|}
\hline Frequência Inicial & Frequência Final & Largura de Banda \\
\hline $902 \mathrm{MHz}$ & $907,5 \mathrm{MHz}$ & $5,5 \mathrm{MHz}$ \\
$915 \mathrm{MHz}$ & $928 \mathrm{MHz}$ & $13 \mathrm{MHz}$ \\
$2400 \mathrm{MHz}$ & $2483,5 \mathrm{MHz}$ & $83,5 \mathrm{MHz}$ \\
$5725 \mathrm{MHz}$ & $5850 \mathrm{MHz}$ & $125 \mathrm{MHz}$ \\
\hline
\end{tabular}

Tabela 1: Frequências disponíveis para comunicação digital por rádio sem autorização da ANATEL

Os padrões IEEE $802.11 \mathrm{~b}$ e $802.11 \mathrm{~g}$ utilizam a faixa de frequência de $2400 \mathrm{MHz}$ através das técnicas de espalhamento espectral DSSS (Direct Sequence Spread Spectrum) e OFDM (Orthogonal Frequency Division Multiplexing). As formas de modulação utilizadas nestes padrões são bem apropriadas para redes domésticas e de pequenos escritórios, pois abordam de maneira satisfatórios os principais entraves envolvidos nestas comunicações - a interferência com as outras redes e o efeito do multipercurso das ondas eletromagnéticas.

A primeira e a segunda faixa de frequência da tabela 1 são comumente utilizadas em aparelhos telefônicos sem fio (cordless), enquanto a ultima, 5,8GHz, é utilizada pela padrão IEEE 802.11a.

Portanto, para escolha da frequência que será utilizada para transmissão digital é necessário verificar sua disponibilidade para comunicação, e em certas ocasiões a autorização da ANATEL. Outra variável importante é a respectiva atenuação de uma onda, com determinada frequência, no espaço livre. Frequências da ordem de GHz sofrem atenuações consideráveis, principalmente em países tropicais com altos indíces pluviométricos, devido a absorção da onda pelas moléculas de água. 
As antenas influenciam o alcance do sistema. Antenas parabólicas apresentam ganhos da ordem de 30dB em relação a fonte isotrópica, enquanto dipolos e monopolos apresentam apenas 3dB. As dimensões limitam a utilização de alguns tipos de antenas. Na seção do Link Budget analisaremos a viabilidade da utilização de antenas parabólicas em VANTs, através da determinação das dimensões da antena em função da frequência da portadora utilizada.

\subsection{Propagação de Ondas}

Algumas ondas de baixa frequência se propagam na superfície terrestre. Estas ondas tem frequência inferior a $2 \mathrm{MHz}$ e são utilizadas para comunicações a longas distâncias. A principal limitação deste tipo de onda é a largura de banda disponível, por isto transmite-se, comumente, apenas voz nesta faixa. A Figura 2 ilustra a propagação deste tipo de onda.

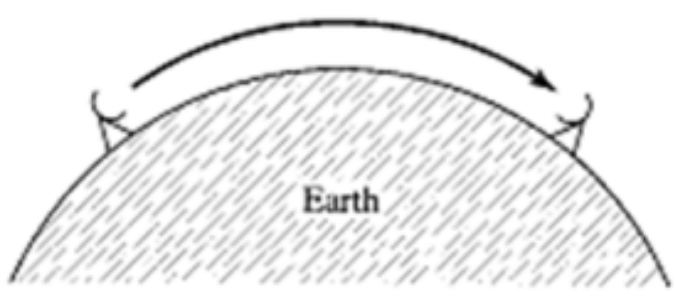

Figura 2: Propagação de Ondas Terrestres $(f \leq 2 M H z)$ - Fonte: [5] pg 421

As ondas ionosféricas estão situadas na faixa de 2 a $30 \mathrm{MHz}$. Estas ondas se propagam por longas distâncias devido as reflexões na ionosfera. Os rádios $\mathrm{CB}$, a rádio BBC (Inglaterra) e a rádio Voice of America transmitem nesta faixa de frequência. A Figura 3 ilustra a propagação deste tipo de onda.

O último tipo de propagação ocorre para ondas com frequência superior a $30 \mathrm{MHz}$, e é denominada propagação por linha de visada (ver Figura 4).

No presente trabalho, em virtude da largura de banda necessária para transmissão de vídeo digital, considerou-se a utilização de frequências superiores a 30MHz. Logo, 


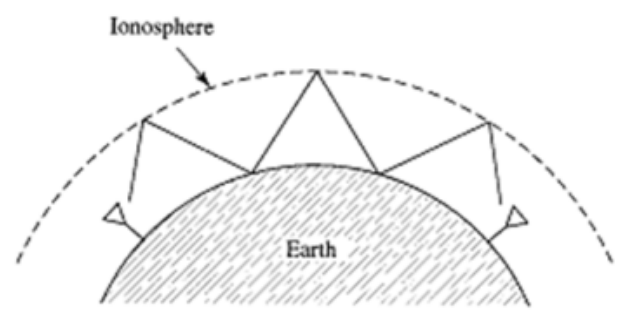

Figura 3: Propagação de Ondas Ionosféricas $(2 M H z \leq f \leq 30 M H z)$ - Fonte: [5] pg 416

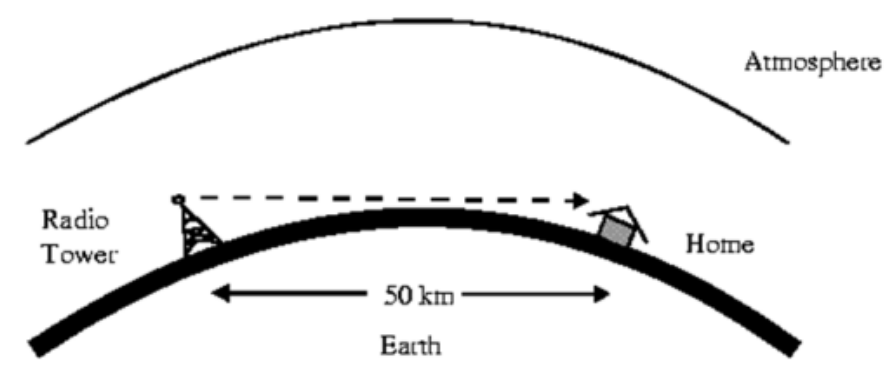

Figura 4: Propagação de Ondas por Linha de Visada $(f \geq 30 M H z)$ - Fonte: [5] pg 420

a propagação ocorrerá por linha de visada.

\subsubsection{Fading de Larga Escala}

O fading de larga ocorre devido a perdas de propagação e ao efeito do shadowing, que será descrito a seguir. Este fenômeno é observado quando o transmissor e o receptor estão afastados por distâncias da ordem de quilômetros.

O modelo de propagação para ondas eletromagnéticas transmitidas em linha de visada com o sinal trafegando no espaço livre é dado pela equação de Friis[12],

$$
P_{r}(d)=\frac{P_{t} G_{r} G_{t} \lambda^{2}}{(4 \pi)^{2} d^{2}}
$$

sendo $\lambda$ o comprimento da onda transmitida, $G_{t}$ o ganho da antena no transmissor, $G_{r}$ o ganho da antena do receptor, $P_{t}$ a potência do transmissor, $d$ a distância entre o transmissor e receptor. Nesta equação $P_{r}$ é a potência observada no receptor.

Convertendo o comprimento de onda, $\lambda$, em frequência através da relação $v=c=$ 
$\lambda f[17]$, desprezando-se os ganhos das antenas, $G_{t}=G_{r}=1$, e manipulando a equação anterior, obtem-se a expressão

$$
P_{t}-P_{r}=a_{0}=20 \log \left(f_{M H z}\right)+20 \log \left(d_{K m}\right)+32,4,
$$

que, por sua vez, descreve a atenuação no espaço livre (em decibéis) de uma onda eletromagnética transmitida por uma fonte isotrópica com frequência $f$ (em MHz) que percorreu uma distância $d(\mathrm{em} \mathrm{Km})$.

Apesar de partir de premissas simples, este modelo fornece uma boa estimação para atenuação do sinal em função da distância entre o transmissor e receptor. Comunicação via satélite, por exemplo, envolve condições muito próximas as consideradas neste modelo. VANTs comumente utilizam um link de comunicação via satélite e outro na frequência de UHF [9][23].

Como podemos observar quanto maior a distância e a frequência, maior será a atenuação, por isso é interessante trabalhar com frequências baixas para evitar perdas excessivas do sinal. A Figura 5 ilustra o efeito da distancia e frequência nas perdas por propagação.

Em sistemas de comunicação via rádio é possível observar que dois nós móveis situados em pontos distintos, mas com mesma distância em relação a estação base podem receber sinais com amplitudes diferentes. Logo, o modelo baseado na equação de Friis não pode explicar este tipo de fenômeno, que em comunicações recebe o nome de shadowing ou sombreamento. Isto ocorre porque cada um dos sinais pode ter se propagado por obstáculos e ambientes diferentes. O que se observa é que o sinal varia aleatoriamente em função da distância entre estação móvel e estação base.

A Equação 3 apresenta um modelo que considera o efeito do shadowing.

$$
a_{0}^{*}=a_{0}+X
$$




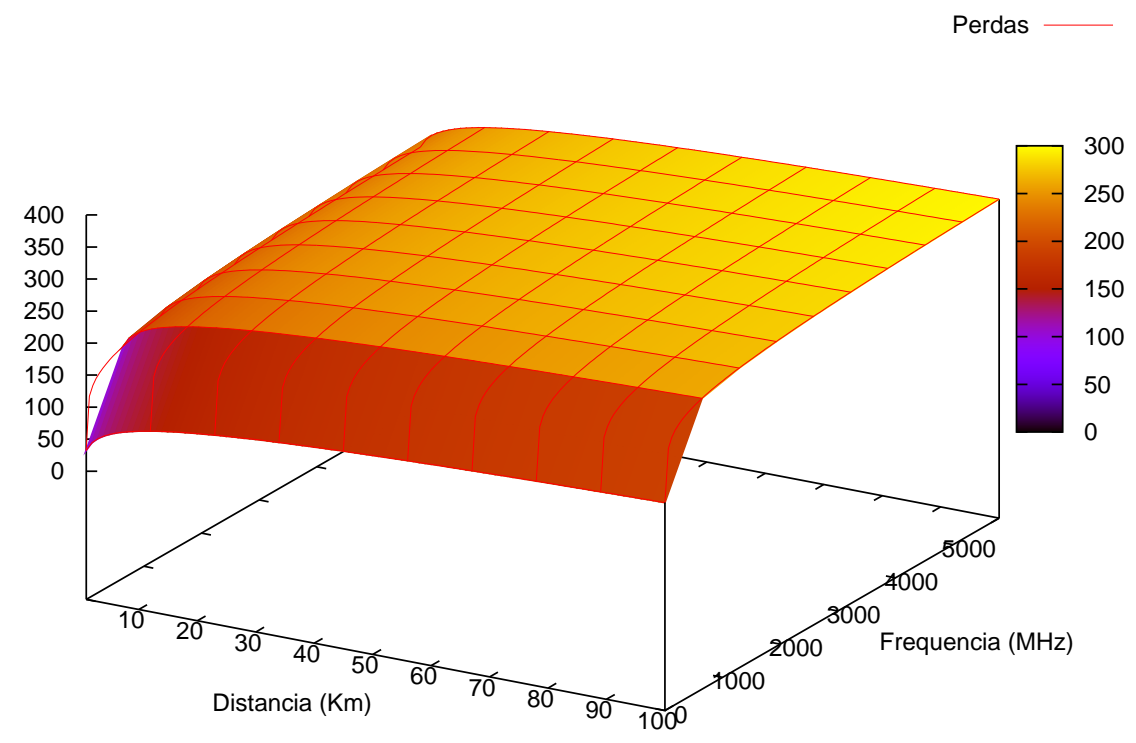

Figura 5: Perdas por propagação de ondas no espaço-livre

A equação acima está em decibéis. O modelo mais usual para shadowing assumem que $X$ é uma variável aleatória com distribuição gaussiana. Tipicamente, a média desta variável é zero e o desvio padrão maior do que 10 dBs [29]. Este modelo é comumente denominado de lognormal porque a distribuição da amplitude $a_{0}^{*}$, antes de convertê-la para decibéis, segue este tipo de distribuição. A Figura 6 ilustra o efeito shadowing. Neste gráfico há o perfil de perdas por propagação de 3 trajetórias diferentes comparadas na mesma distância. Para geração deste gráfico considerou-se a frequência da portadora de $1500 \mathrm{MHz}$ e que a variável aleatória responsável pelo efeito do sombreamento possuía média zero e desvio padrão igual a 3dB.

Okumura [19] realizou vários experimentos para determinação do comportamento do canal de comunicação em ambientes urbanos. A finalidade dos experimentos era encontrar a área coberta e a altura das antenas utilizadas em comunicações móveis. O trabalho se foca em redes com nós móveis cuja frequência fica na faixa de 500 a 1500MHz. As células consideradas são da ordem de 1 a 100Km e a altura da antena na 


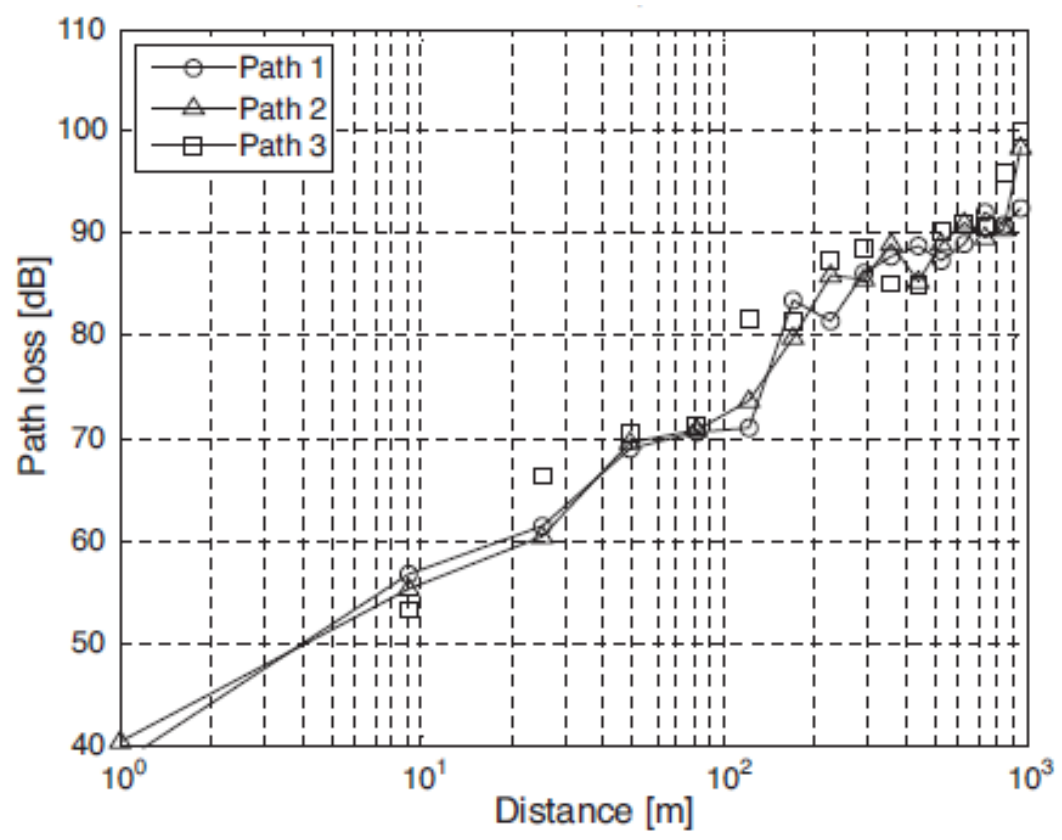

Figura 6: Efeito do Shadowing

faixa de 30 a 1000m do solo. Apesar disto, o modelo pode ser extrapolado tanto para frequência de operação quanto para a altura da antena.

A equação proposta por Okumura é

$$
a_{O K}=a_{0}+A_{M U}(f, d)-G_{R x}-G_{T x}+G_{A R E A}
$$

sendo $a_{0}$ a atenuação no espaço-livre, $A_{M U}$ é a mediana da atenuação relativa a perda no espaço-livre, $G_{A R E A}$ é o ganho relativo ao tipo de ambiente escolhido. Estes valores foram obtidos empiricamente e foram disponibilizados em gráficos no trabalho de Okumura. $G_{R x}$ e $G_{T x}$ são fatores de ganhos das antenas da estação móvel e da base, respectivamente, em função da altura em relação ao solo de cada uma delas.

As antenas da estação base com alturas, $h_{t e}$, variando de 30 a $1000 \mathrm{~m}$ o fator de ganho da antena é

$$
G_{T x}=20 \log \left(\frac{h_{t e}}{200}\right)
$$


O fator de ganho da antena da estação móvel possui duas equações. A primeira é aplicada para alturas $h_{r e}$ menores do que $3 \mathrm{~m}$,

$$
G_{R x}=10 \log \left(\frac{h_{r e}}{3}\right)
$$

enquanto a segunda é utilizada para alturas entre 3 e $10 \mathrm{~m}$,

$$
G_{R x}=20 \log \left(\frac{h_{r e}}{3}\right)
$$

O modelo de Okumura foi extendido por Hata [8] para tratar ambientes suburbanos e áreas abertas, além dos ambientes urbanos. Para frequência de operação $f_{c}$ em $\mathrm{MHz}$ e uma distância $d$ em metros, a perda descrita pelo modelo de Hata em ambientes urbanos é

$a_{H A T A, U R B A N O}(d)=69.55+26.16 \log \left(f_{c}\right)-13.82 \log \left(h_{T x}\right)-C_{R x}+\left(44.9-6.55 \log \left(h_{T x}\right)\right) \log (d)$.

Nesta equação $C_{R} x$ é o coeficiente de correlação da antena da estação móvel. Para coberturas pequenas vale a relação,

$$
C_{R x}=0.8+\left(1.1 \log \left(f_{c}\right)-0.7\right) h_{R x}-1.56 \log \left(f_{c}\right) .
$$

O valor do coeficiente para grandes coberturas é

$$
C_{R x}=8.29\left(\log \left(1.54 h_{R x}\right)\right)^{2}-1.1
$$

para frequências entre 150 a $200 \mathrm{MHz}$, e

$$
C_{R x}=3.2\left(\log \left(11.74 h_{R x}\right)\right)^{2}-4.97
$$


para distâncias entre 200 a $1500 \mathrm{MHz}$.

Em meios suburbanos e áreas abertas o modelo de Hata considera perdas dada por

$$
a_{H A T A, S U B U R B A N O}(d)=a_{H A T A, U R B A N O}(d)-2\left(\log \frac{f_{c}}{28}\right)^{2}-5.4,
$$

para ambientes suburbanos e

$$
a_{H A T A, A A}(d)=a_{H A T A, U R B A N O}(d)-4.78\left(\log \left(f_{c}\right)\right)^{2}+18.33 \log \left(f_{c}\right)-40.97 \text {. }
$$

A Figura 7 ilustra as perdas por propagação no modelo de Hata para a frequência de operação de $1500 \mathrm{MHz}$ para os três perfis de terreno citados anteriormente. Os ambientes urbanos são os que possuem perdas mais elevadas devido a grande quantidade de obstáculos entre a estação base e a estação móvel. Quando não há linha de visada as ondas que chegam no receptor sofreram reflexões e difrações o que justifica o maior nível de atenuação exibido na curva.

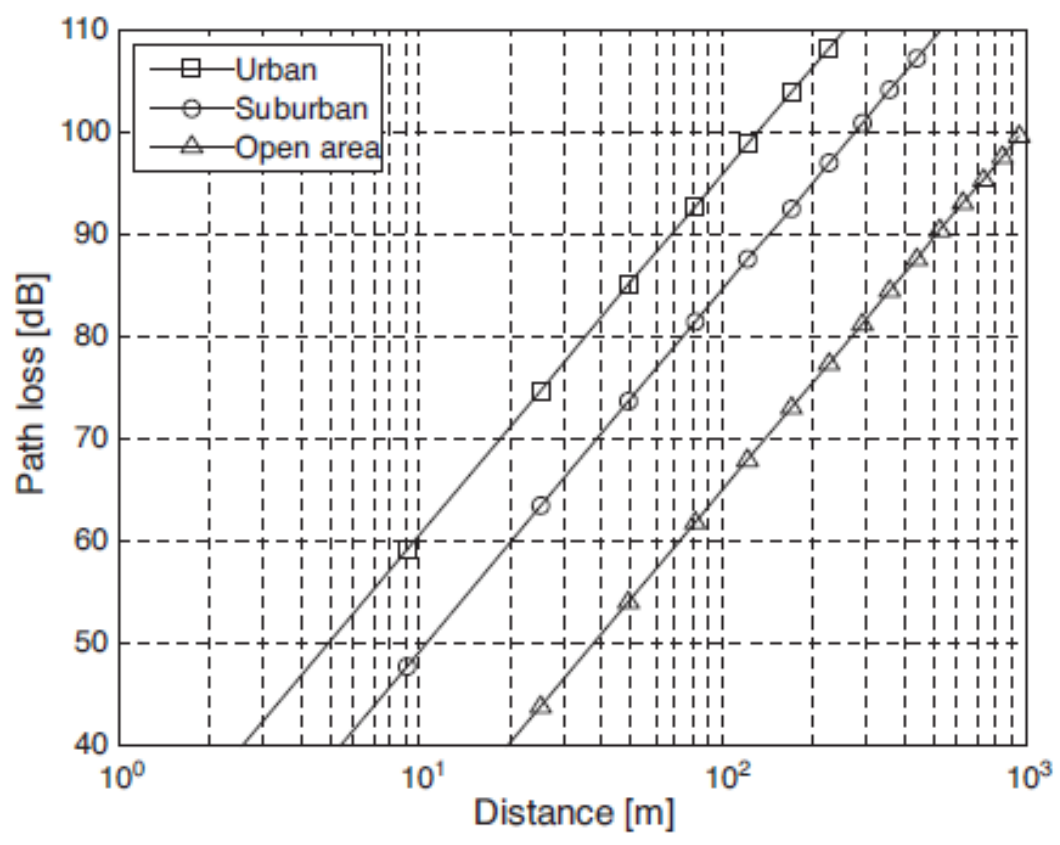

Figura 7: Perdas no modelo de Hata

O modelo de perdas de propagação do padrão 802.16d [29], WiMax, é baseado no 
efeito de shadowing. O modelo aborda o comporta de três tipos de terreno, conforme a Tabela 2 exibida a seguir.

\begin{tabular}{|c|c|}
\hline Tipo & Descrição do Terreno \\
\hline A & Terrenos acidentados com alta densidade de árvores \\
\hline B & Terrenos Intermediários \\
\hline C & Terrenos Planos com baixa densidade de árvores \\
\hline
\end{tabular}

Tabela 2: Configurações de Terreno para WiMax

A equação que define a perda por propagação no modelo do padrão 802.16d é

$$
a_{802.16}(d)=a_{0}\left(d_{0}\right)+10 \gamma \log _{10}\left(\frac{d}{d_{0}}\right)+C_{f}+G_{R x}
$$

Nesta equação a $d_{0}=10 m$ e $\gamma=a-b h_{T x}+c / h_{T x}$. As constantes a, b e c se referem aos respectivos tipos de terreno e seus valores seguem na Tabela 3.

\begin{tabular}{|c|c|c|c|}
\hline Parâmetro & Terreno A & Terreno B & Terreno C \\
\hline $\mathrm{a}$ & 4.6 & 4 & 3.6 \\
$\mathrm{~b}$ & 0.0075 & 0.0065 & 0.005 \\
$\mathrm{c}$ & 12.6 & 17.1 & 20 \\
\hline
\end{tabular}

Tabela 3: Parâmetros por tipo de terreno no modelo de perdas por propagação do padrão 802.16d

A altura da antena, $h_{T} x$, varia de 10 a $80 \mathrm{~m}$. O parâmetro $C_{f}=6 \log _{10}\left(f_{c} / 2000\right)$ é o coeficiente de correlação com a frequência da portadora $f_{c}$ em MHz. O coeficiente de correlação da antena, $G_{R x}$, pode ser determinado pelos valores obtidos por Okumura, ou pelas medidas realizadas pela AT\&T que definem

$$
G_{R x}=-10.8 \log _{10}\left(h_{R x} / 2\right)
$$


para terrenos do tipo A e B e

$$
G_{R x}=-20 \log _{10}\left(h_{R x \mid / 2),(16)}\right.
$$

para terrenos do tipo C.

\subsubsection{Fading de Pequena Escala}

Fading de Pequena Escala se refere as flutuações observadas na amplitude de um sinal observado causadas por leves mudanças no tempo ou na distância. Geralmente, este fenômeno ocorre porque o sinal que chega a um receptor é o somatório de várias ondas eletromagnéticas que percorreram diferentes trajetórias. Cada uma destas ondas que constituiram o sinal observado no receptor apresentará fase (delay) e atenuação diferentes.

Um canal com o efeito do multipercurso pode ser caracterizado pelo seu power delay profile (PDP). Por exemplo, o modelo ITU-R considera que o sinal no receptor será composto por quatro ondas, cujos atrasos e potências são dadas pela Tabela 4 .

\begin{tabular}{|c|c|c|}
\hline Onda & Atraso Relativo (ns) & Potência Média $(\mathrm{dB})$ \\
\hline 1 & 0 & 0.0 \\
2 & 110 & -9.7 \\
3 & 190 & -19.2 \\
4 & 410 & -22.8 \\
\hline
\end{tabular}

Tabela 4: Power Delay Profile no modelo ITU-R para pedestres

Sejam $\tau_{k}$ a k-ésima onda, $a_{k}$ a amplitude e $P\left(\tau_{k}\right)$ a potência. O mean excess delay é definido por

$$
\bar{\tau}=\frac{\sum a_{k}^{2} \tau_{k}}{\sum a_{k}^{2}}=\frac{\sum P\left(\tau_{k}\right) \tau_{k}}{\sum P\left(t_{k}\right)} .
$$

O $R M S$ delay spread $\sigma_{\tau}$ é 


$$
\sigma_{\tau}=\sqrt{\bar{\tau}^{2}-\bar{\tau}^{2}}
$$

onde

$$
\bar{\tau}^{2}=\frac{\sum \tau_{k}^{2} P\left(\tau_{k}\right)}{\sum P\left(\tau_{k}\right)} .
$$

Com $\sigma_{\tau}$ definimos a largura de banda coerente, $B_{c}$,

$$
B_{c} \approx \frac{1}{\sigma_{\tau}}
$$

Dependendo da relação entre $B_{c}$ e a largura de banda utilizada na transmissão, $\sigma_{\tau}$ e o período utilizado para transmitir cada símbolo o desempenho do enlace pode ser alterado.

O modelo do canal Riciano considera que o sinal observado no receptor é composto por um sinal de maior potência transmitido em linha de visada, e outro sinal estocástico resultante das outras ondas que se propagaram por outros percursos. A equação que descreve o sinal recebido é

$$
P_{r}=P_{r 0}+W_{1}+j W_{2}
$$

onde $j=\sqrt{-1}$ e $W_{1}$ e $W_{2}$ são variáveis aleatórias com distribuição gaussinana com média zero. Vale ressaltar que $W_{1}$ e $W_{2}$ são independentes e identicamente distribuidas, ou seja, não possuem correlação nem autocorrelação, por esta razão o sinal $P_{r}$ possui distribuição riciana.

\subsection{Técnicas de Diversidade na Transmissão}

Há, basicamente, três tipos de diversidade que pode ser explorada em uma transmissão de dados:

- Diversidade Temporal 
- Diversidade em Frequência

- Diversidade Espacial

A diversidade temporal se caracteriza pela replicação do sinal no domínio do tempo, ou seja, transmitir as mesmas informações mais de uma vez com o intuito de minimizar a perda de bits. Este esquema, naturalmente, diminui a taxa de transmissão efetiva de um link de comunicação.

O segundo tipo de redundância se dá quando réplicas do sinal são transmitidas em várias frequências. Apesar de a taxa de transmissão se manter constante neste esquema, haverá um desperdício de banda espectral, o que na maioria dos casos é intolerável.

O último tipo, a redundância espacial, não diminui a taxa de transmissão e, também, não exige maior largura de banda. Este tipo de redundância pode ser usada para transmitir maior quantidade de informação utilizando mais antenas. A Figura 8 ilustra as configurações possíveis das antenas no receptor e transmissor, e suas respectivas nomenclaturas.

SISO (Single Input Single Output) é o esquema padrão no qual não há diversidade espacial [4]. SIMO (Single Input Multiple Output) e MISO (Multiple Input Single Output) exploram a redundância em apenas um dos nós. MIMO é a abreviatura em inglês para Multiple Input Multiple Output que explora a redundância entre o transmissor e receptor.

Sejam $M_{t}$ o número de antenas no transmissor, $M_{r}$ o número de antenas no receptor, $E_{s} / N_{0}$ a relação sinal-ruído e $M=M A X\left(M_{r}, M_{t}\right)$.A capacidade (bits/Hz) do SIMO é

$$
C=\log _{2}\left(1+M_{r} E_{s} / N_{0}\right) .
$$

A capacidade do MISO é

$$
C=\log _{2}\left(1+M_{t} E_{s} / N_{0}\right) .
$$




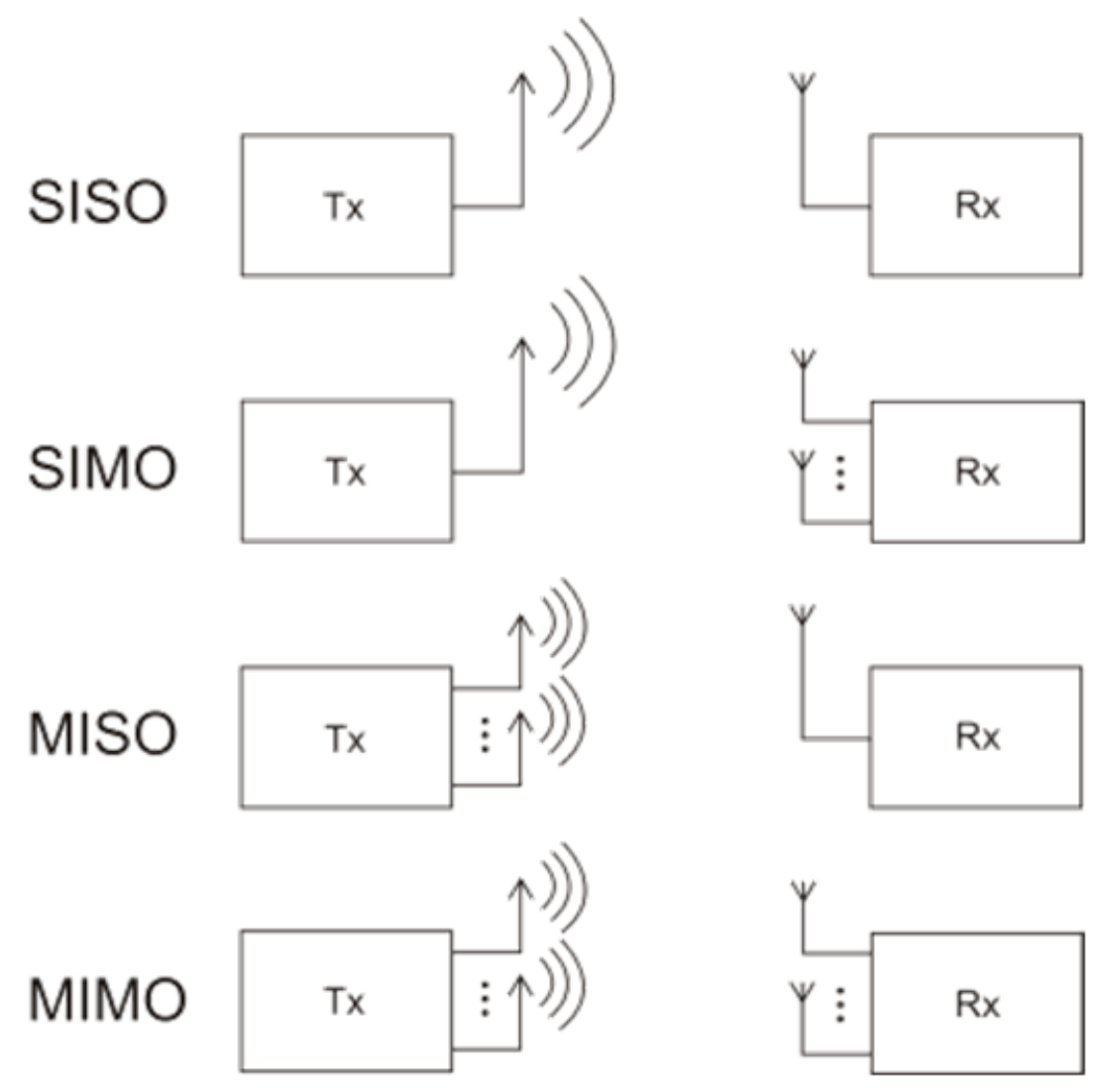

Figura 8: Antenas e Redundância Espacial

A capacidade do MIMO é

$$
C=M \log _{2}\left(1+E_{s} / N_{0}\right) .
$$

Usando estas técnicas é possível aumentar a taxa de transferência de dados. Como no presente trabalho os equipamentos instalados no VANT possuem restrições de tamanho e peso, a diversidade espacial poderia ser explorada apenas na estação terrestre, no entanto, será utilizado em nossa análise apenas o esquema (SISO). Estas restrições, também, estão presentes nos sistemas de comunicação móvel[7]. 


\subsection{Esquemas de Modulação}

Considere uma informação digital definida por uma sequência de bits. Para transmitir esta informação em um canal necessitamos de uma regra de mapeamento entre os bits e os sinais correspondentes. Esta regra de mapeamento é denominada esquema de modulação digital [11]. Um esquema de modulação digital linear é caracterizado pelo sinal complexo em banda base

$$
s(t)=\sum_{k=1}^{K} s_{k} g_{k}(t)
$$

onde $s_{k}$ é o simbolo complexo que carrega a informação. O esquema de modulação é chamado linear porque é um mapeamento linear do vetor $s=\left(s_{1}, s_{2}, \ldots, s_{n}\right)^{T}$ dos símbolos transmitidos para o sinal contínuo s(t). As constelações de sinais são utilizadas para transmitir um dos $M$ possíveis pontos, sendo $M$ uma potência de dois. Logo cada símbolo carrega $\log _{2}(M)$ bits. A regra que determina a correspondência entre símbolos e pontos da constelação é denominada symbol mapping e o dispositivo encarregado de fazer esta tarefa é o symbol mapper.

As principais técnicas de modulação digital são:

- QAM (Quadrature Amplitude Modulation)

- PSK (Phase Shift Keying)

- FSK (Frequency Shift Keying)

A modulação QAM consiste na transmissão de duas ondas de mesma frequência defasadas, tipicamente, de $90^{\circ}$ com a amplitude variando. Esta técnica foi utilizada em modens para conexão dial-up com a finalidade de aproveitar melhor a banda disponível nos fios de cobre dos sistemas telefônicos. A modulação PSK altera a fase de uma onda para indicar a transição entre bits diferentes, enquanto a FSK usa mudanças de frequência para transmitir bits. Há um trade-off entre aproveitamento da banda e susceptibilidade ao ruído que delimita a escolha da modulação. A Figura 9 ilustra um 
diagrama de constelações dos tipos de modulação QAM.

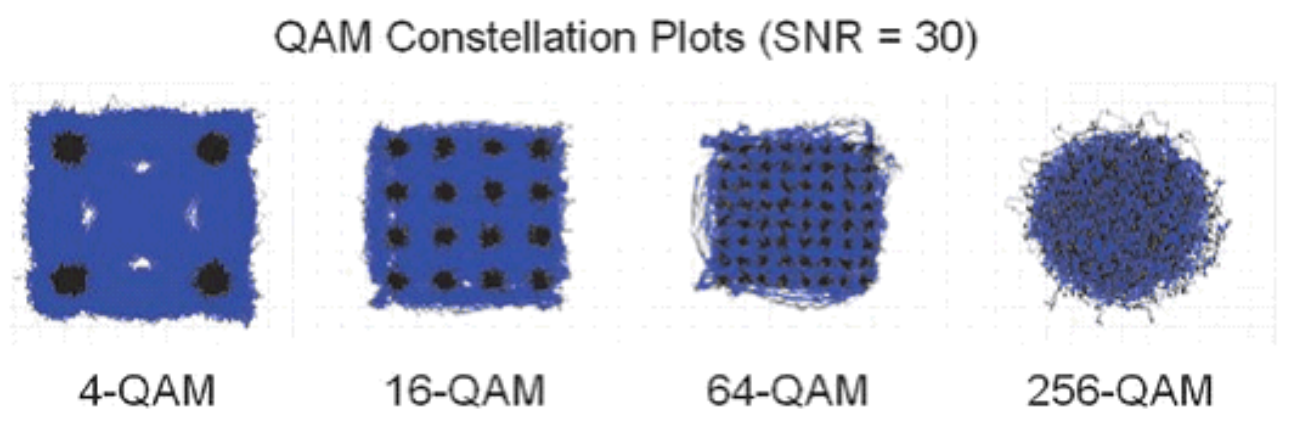

Figura 9: Diagrama de Constelações para a Modulação QAM

\section{$3.5 \quad$ OFDM}

Os primeiros métodos de transmissão que exploravam subportadoras ortogonais simultâneas apresentavam grande ineficiencia em relação a utilização do espectro. As subportadoras por não serem entrelaçadas ocupavam grande largura de banda e transmitiam pouca informação. O método OFDM, por sua vez, utiliza subportadoras entrelaçadas de uma maneira que evite a interferência entre elas e maximize a utilização do espectro. Atualmente, o padrão brasileiro de TV Digital e o europeu (DVB-T) utilizam a técnica OFDM [3].

Considerando que serão transmitidos $N$ simbolos $X_{k}, k \in 0 . . N-1$. Cada símbolo $X_{k}$ será transmitido com uma subportadora de frequência $f_{k}$ [28]. O sinal OFDM no domínio do tempo será

$$
x(t)=\sum_{k=0}^{N-1} X_{k} e^{j 2_{k} t} .
$$

Amostrando este sinal a cada $T_{s}$ unidades de tempo obtem-se

$$
x\left(n T_{s}\right)=\sum_{k=0}^{N-1} X_{k} e^{j 2_{k} n T_{s}} .
$$


Se as subportadoras estão espaçadas uniformemente pela frequência $f_{s}$

$$
x\left(n T_{s}\right)=\sum_{k=0}^{N-1} X_{k} e^{j 2_{s} n T_{s}} .
$$

Como $f_{s}=1 /\left(N T_{s}\right)$, o sinal OFDM é

$$
x_{n}=\sum_{k=0}^{N-1} X_{k} e^{j 2 / N} .
$$

O procedimento acima é uma transformada inversa de fourier e pode ser realizado através de algoritmos otimizados, como o Fast Fourier Transform, ou por meio de circuitos especializados. A Figura 10 ilustra o espectro gerado pelas subportadoras entrelaçadas.

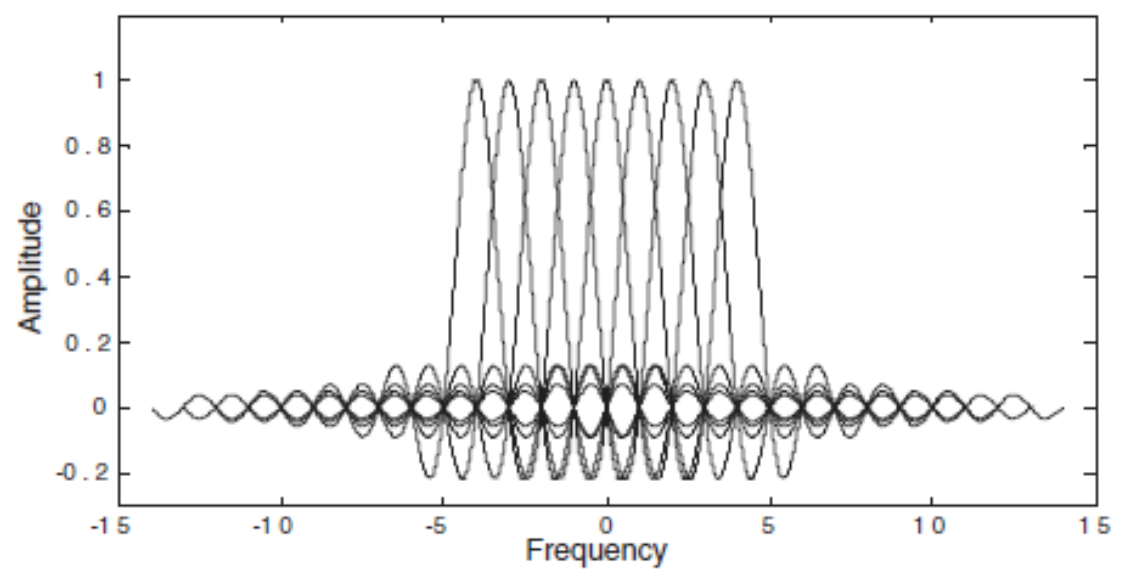

Figura 10: Subportadoras Entrelaçadas

Este sinal gerado estará em banda base. Tipicamente, será necessário converter este sinal para uma frequência superior através de um circuito do tipo up-converter. Após esta etapa todas as subportadoras estarão ao redor da portadora selecionada.

O conjunto dos $N$ simbolos transmitidos por vez será denominado frame. Quando se trabalha com circuitos digitais é interessante utilizar frames com quantidade de subportadoras que seja uma potência de 2 para utilização do método FFT. 
Para que não haja interferência entre quadros transmitidos sequencialmente utilizase um intervalo de guarda. Há duas possibilidades. O método do prefixo cíclico repete os símbolos provenientes do final do quadro no começo do mesmo, conforme exibido na Figura 11. O outro procedimento é a inserção de zeros nas subportadoras do ínicio e fim do quadro. Apesar de gerar overhead no enlace estes procedimentos aumentam o desempenho do procedimento de detecção do sistema de transmissão.

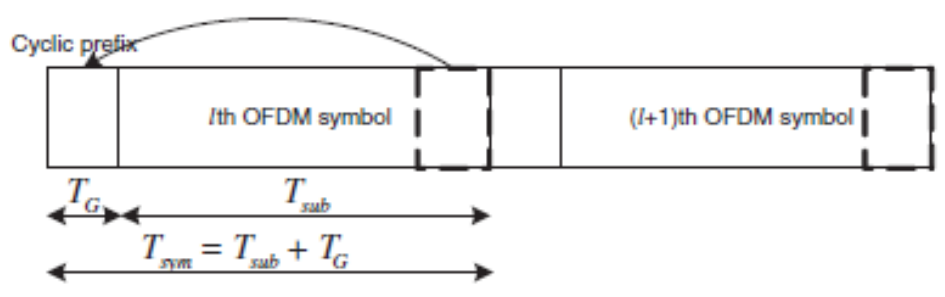

Figura 11: Prefixo Cíclico

Uma deficiência do método de transmissão OFDM é o aumento de picos em relação a potência média do sinal. Este fator se torna problemático quando o sinal passa por amplificadores de potencia antes de ser transmitido. Os amplificadores respondem muitas vezes de forma não-linear introduzindo distorções não desejadas no sinal amplificado quando há picos abruptos no sinal. Além disto, os conversores analógico-digital não funcionarão apropriadamente. Para contornar este problema utiliza-se mapeamentos de símbolos mais complexos através de técnicas de codificação que mitiguem a ocorrência destes picos. A Figura 12 ilustra estes picos de sinais no domínio do tempo.

\subsection{MDE}

Com o surgimento das linguagens de programação, como C e Fortran, foi possível aumentar o nível de abstração ao desenvolver aplicações sem se preocupar com detalhes específicos do hardware. No entanto, estas linguagens não foram capazes de fornecer abstrações ao nível do espaço da solução que é caracterizado por conceitos definidos no domínio da aplicação [22]. 


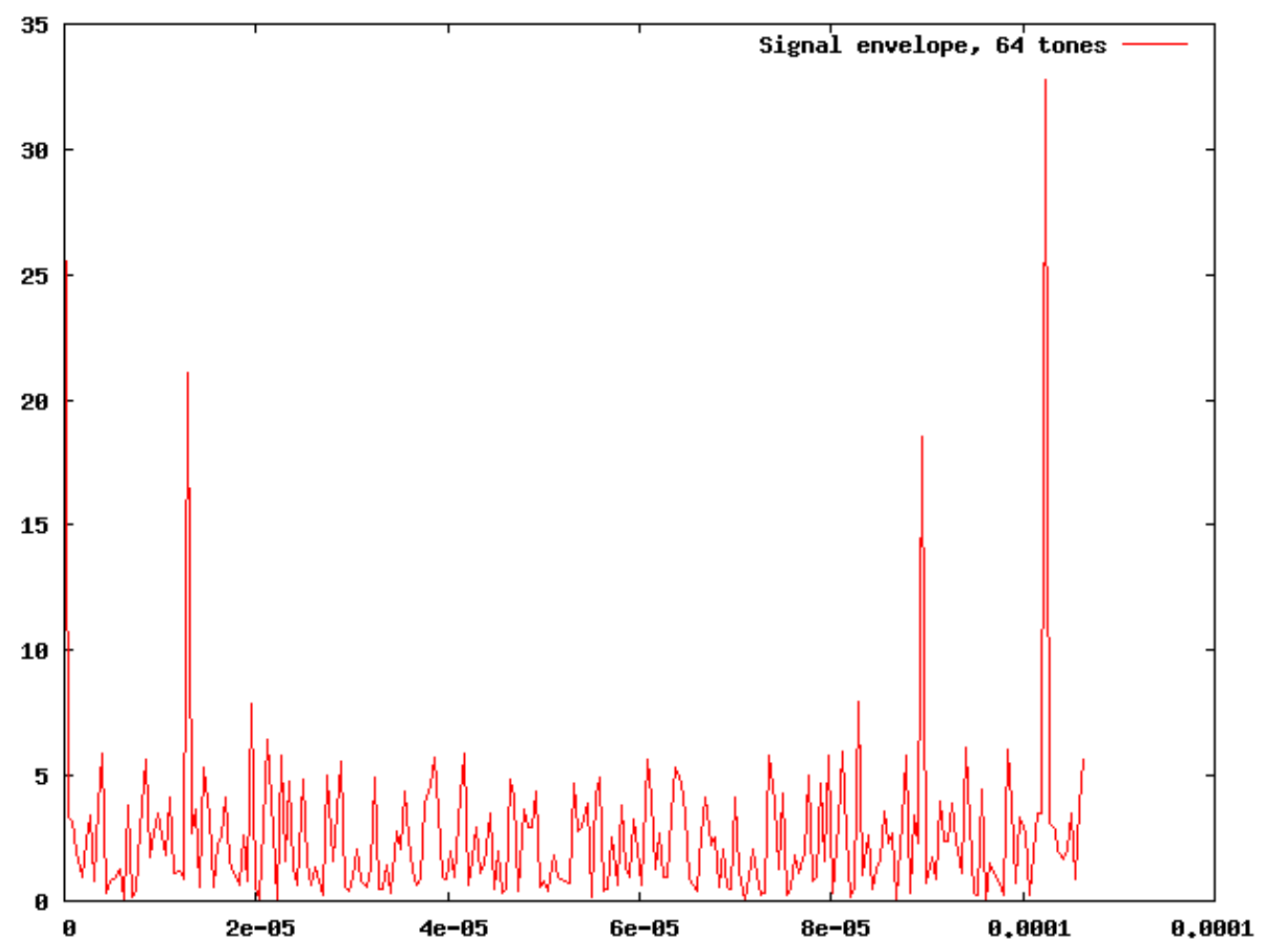

Figura 12: Picos do Sinal OFDM

MDE é a sigla para Model-Driven Engineering. Estas tecnologias promissoras apresentam uma abordagem que possibilita o desenvolvimento de aplicações em um nível próximo ao que o especialista no problema está habituado. Por exemplo, aplicações aeroespaciais, biológicas, financeiras e de telecomunicações podem ser desenvolvidas por meio de $M D E$. Uma grande vantagem em relação a esta abordagem é que os erros no domínio da aplicação podem ser detectados no ínicio do projeto através deste tipo de ferramenta. A principal motivação por trás da utilização de MDE é o aumento de eficiência na criação de aplicações. 


\section{Solução Proposta}

\subsection{Arquitetura da Solução}

No presente trabalho será adotada uma arquitetura superheteródina que é a mais popular entre os transceptores [27]. O receptor converte um sinal em Rádio-Frequência para um sinal em Frequência Intermediária, ou banda base, através de um circuito não-linear denominado mixer. O transmissor transforma um sinal em Frequência Intermediária em um sinal de Rádio-Frequência através de um outro circuito não-linear.

Pode-se destacar duas vantagens desta arquitetura que justificam sua aplicação ao presente trabalho. A primeira vantagem reside no fato de que podemos utilizar o mesmo oscilador tanto para o mixer do transmissor quanto do receptor. A outra vantagem é que o sinal em Frequência Intermediária pode ser gerado e trabalhado a partir de circuitos digitais mais conversores Analógico-Digital e Digital-Analógico.

O bloco composto pelo encoder, decoder, FFT e IFFT no lado direito da Figura 13 corresponde a parte digital do transceptor. O codificador e o decodificador são responsáveis por adicionar e tratar a redundância e fazer a verificação de erros. Será a técnica do prefixo cíclico e a inserção de 8 tons pilotos dentro do frame OFDM.

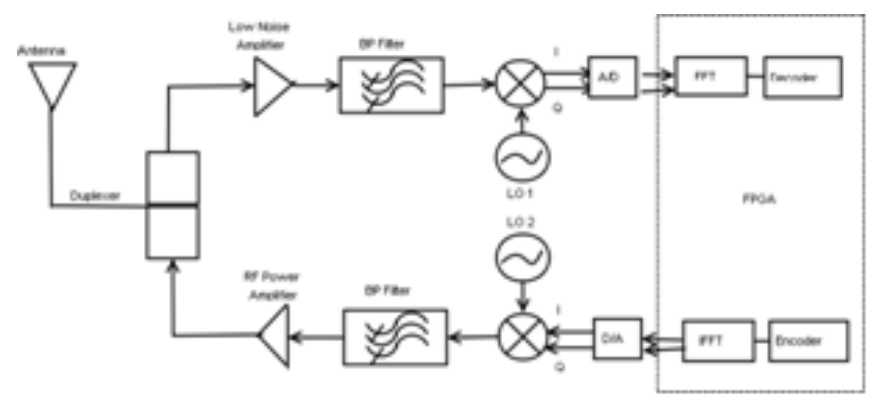

Figura 13: Diagrama de Blocos do Transceptor

O principal bloco da técnica de transmissão OFDM é o que realiza a transformada de fourier. Os DSPs possuem blocos otimizados para o cálculo da transformada de fourier denominadas $M A C s$ responsáveis por operações de multiplicação e acumulação 
(soma). Soluções em FPGAs podem compartilhar elementos do hardware reponsável pela FFT e a IFFT diminuindo o número de blocos lógicos utilizados no chip, além disso pode-se utilizar várias unidades. Além disso, é possível criar vários blocos $M A C s$ e executá-los em poucos ciclos de clock através dos FPGAs modernos. A Figura 14 ilustra as diferenças entre FPGAs e DSPs.

Processador DSP

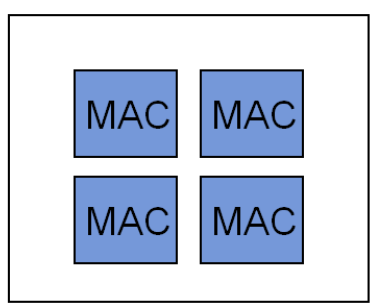

- 1-8 Multiplicadores

Precisa de Multiplos ciclos de clock para mais de 8 multiplicaçoes
FPGA

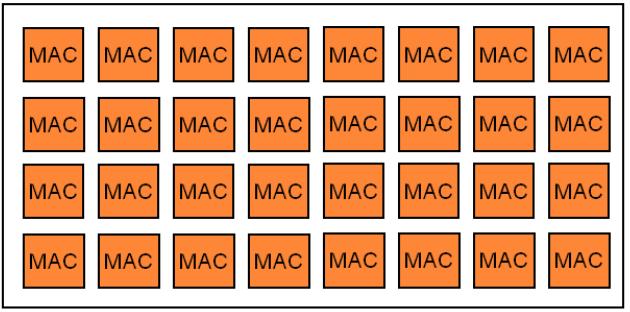

- Implementa várias operações de multiplicação em paralelo

Figura 14: DSPs e FPGAs

Pelas razões apontadas anteriormente julgou-se mais adequada a utilização de FPGAs para realização da lógica digital do nosso transceptor. Uma solução com DSPs só seria cogitada se houvesse necessidade de produção em grandes quantidades, o que não é o caso.

\subsection{A ferramenta Matlab/Simulink}

O Matlab possibilita o desenvolvimento de aplicações através de uma ferramenta $M D E$ denominada Simulink. No presente trabalho utilizou-se os toolboxes de processamento digital de sinais $(D S P)$ e comunicações.

Com o auxilio desta ferramenta, também, será possível realizar simulações do comportamento do modelo proposto para alguns tipos de ambientes. Neste caso, os ambien- 
tes distintos são caracterizados por condições de interferência no sinal que modelaremos através de certos tipos de ruído.

Embora o presente trabalho tenha como foco apenas a especificação da solução para o problema do enlace digital, como tudo foi feito no Simulink será possível migrar a solução para um protótipo em hardware por meio de duas alternativas. A primeira delas se daria por meio da geração de código em C que seria adaptado para algum microprocessador. A outra alternativa seria por meio da geração de códigos VHDL que seriam utilizados em hardwares reprogramáveis, FPGAs.

Será utilizado o método da Simulação de Monte Carlo para determinação do desempenho do enlace para cada configuração de ruído. Para isto, foi simulado o comportamento do enlace por um período relativamente longo para cada uma das configurações e obtivemos as respectivas taxas de perda de bit.

O frame do OFDM utilizado foi de 256 simbolos sendo $1 / 4$ destes simbolos utilizados como redundância através da técnica do prefixo cíclico e tons pilotos, o que acarretou em 192 símbolos úteis para transmissão de dados. Os 192 símbolos serão gerados por meio de um gerador de números pseudo-aleatórios do Simulink cuja taxa de transmissão foi de um frame a cada $6 \mathrm{MHz}$. A quantidade de informação por símbolo, por sua vez, variou entre as opções 4, 16 e 64 .

\subsection{Detalhes da Solução Adotada}

A solução gerada teve como base o modelo disponível em [18]. A Figura 15 ilustra o modelo gerado no Simulink a partir deste exemplo.

Em seguida, seguirá a descrição do funcionamento e da parametrização de cada um dos blocos do modelo gerado pelo Simulink. 


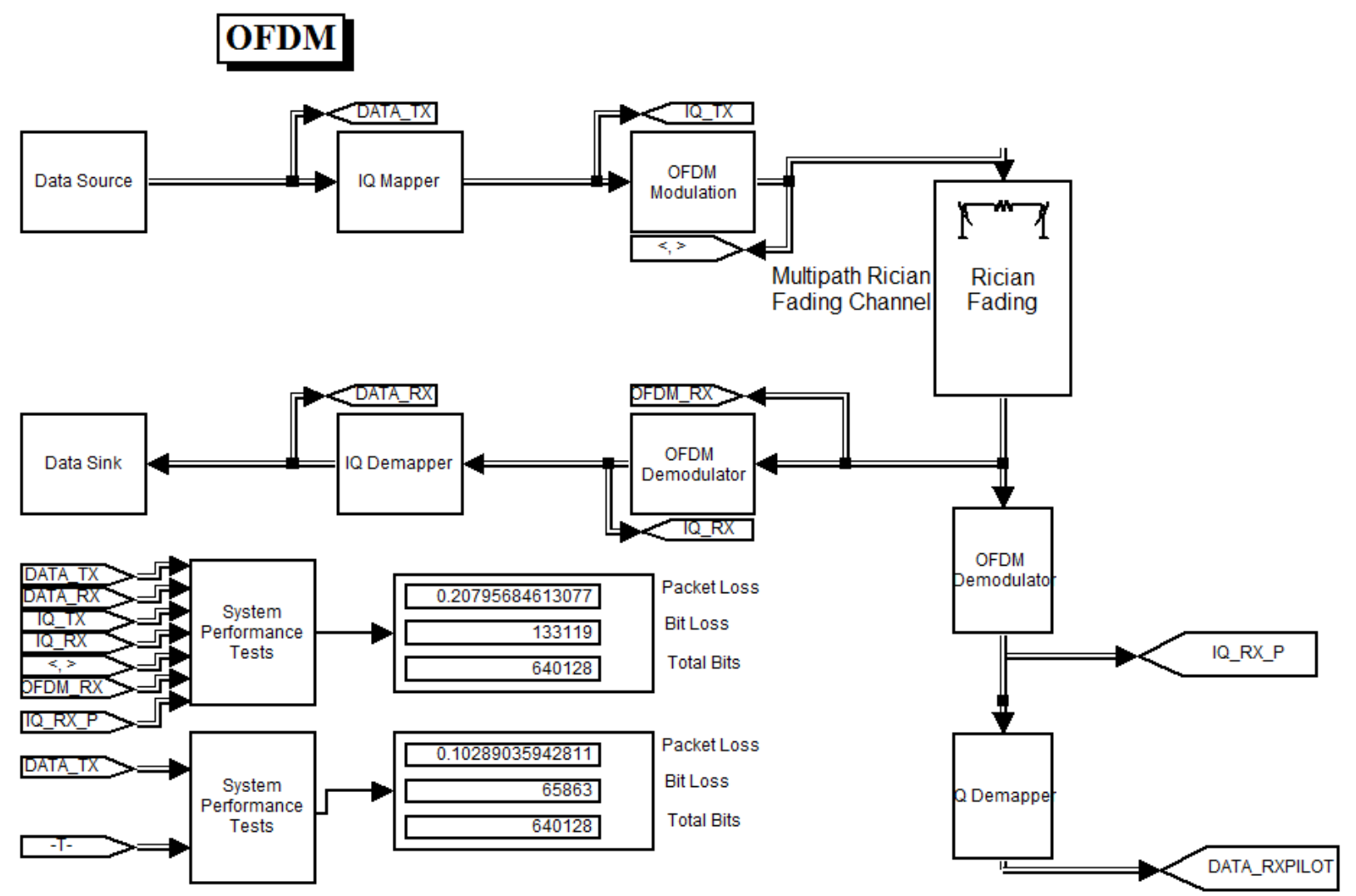

Figura 15: Modelo do Simulink gerado para o transmissor e receptor

\subsubsection{Data Source}

O bloco Data Source é responsável pela geração do sinal aleatório que entra no transmissor para avaliar o desempenho do mesmo (taxa de perda de bits). Utiliza 192 subportadoras, sendo que cada símbolo corresponde a valores entre 0 a $M-1$. A Tabela 5 abaixo descreve as configurações da modulação M-QAM que serão avaliadas no modelo proposto. O sinal em banda base está limitado a $6 \mathrm{MHz}$.

\begin{tabular}{|c|c|}
\hline$M$ & Número de Bits $\left(\log _{2}(M)\right)$ \\
\hline 4 & 2 \\
\hline 16 & 4 \\
\hline 64 & 6 \\
\hline
\end{tabular}

Tabela 5: Configurações de M-QAM 


\subsubsection{IQ Mapper}

O bloco IQ Mapper transforma a sequência de bits gerada pelo bloco Data Source, discutido anteriormente, em uma sequência de símbolos representados por números complexos.

O conjunto dos valores que um símbolo M-QAM pode assumir é descrito por

$$
\alpha_{M Q A M}= \pm(2 m-1) \pm(2 m-1) j
$$

onde $m \in\left\{1, \ldots, \frac{\sqrt{M}}{2}\right\}$.

A energia média dos M símbolos é,

$$
E_{M Q A M}=\frac{\sum \alpha_{M Q A M}}{M}=\frac{2}{3} M-1
$$

Foi realizado um tratamento para que os diferentes tipos de modulação M-QAM gerem sinais com a mesma energia. Para tanto, foi multiplicado o sinal gerado pela constante

$$
u=\sqrt{\frac{3}{2} \frac{1}{(M-1)}}
$$

\subsubsection{OFDM Modulation Block}

O bloco OFDM Modulation Block é responsável pela transformação dos símbolos (no domínio da frequência) para o domínio do tempo através de uma Inverse Fast Fourier Transform (IFFT). A última parte deste bloco adiciona o prefixo cíclico ao sinal no domínio do tempo. A Figura 16 ilustra a composição deste bloco. 


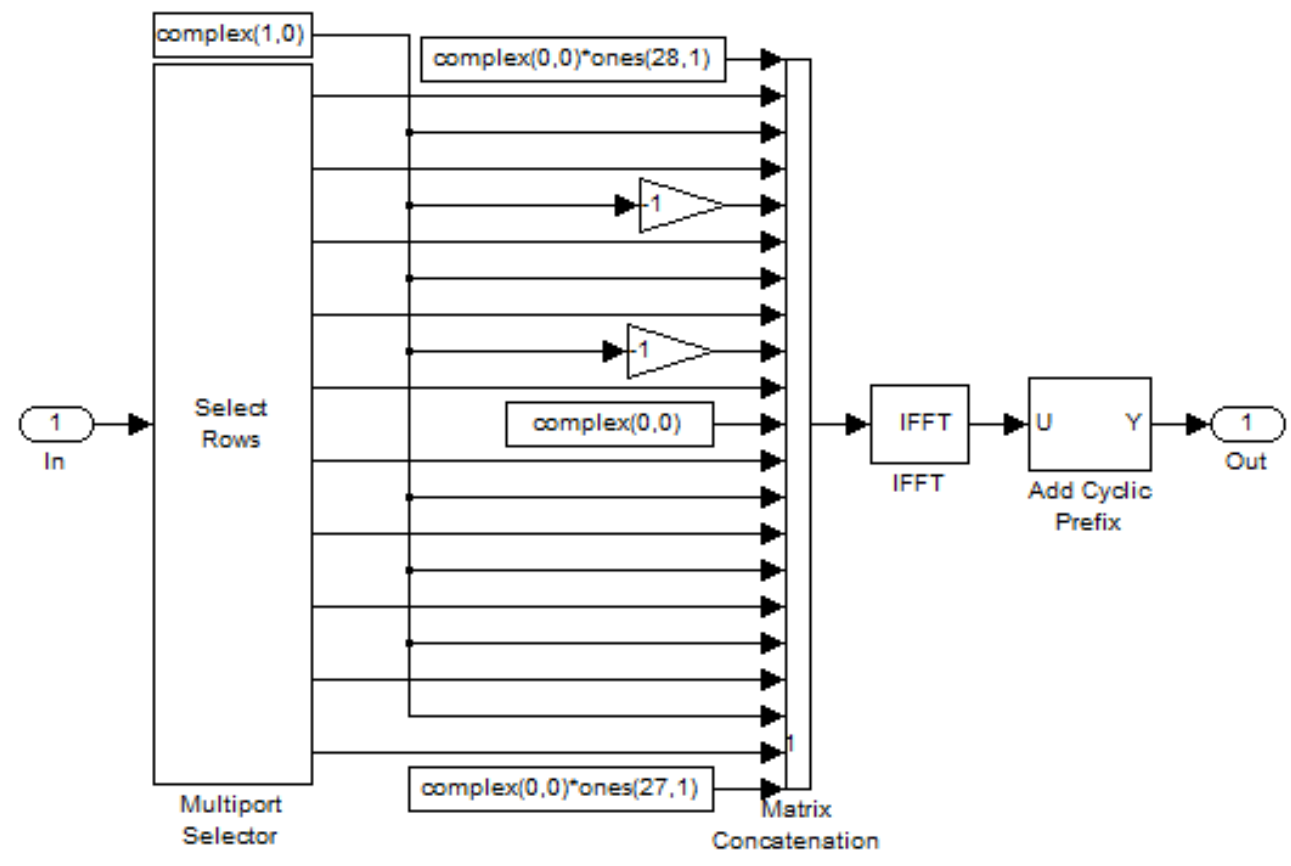

Figura 16: Transformação de sinal no domínio da frequência para o domínio do tempo

\subsubsection{OFDM Demodulator}

O bloco OFDM Demodulator transforma o sinal em dominio do tempo proveniente do canal para o domínio da frequência. Para isto, é utilizada a transformada direta, FFT. No modelo utilizou-se dois blocos demoduladores. A diferença entre os dois blocos está no fato de que um destes blocos estima o comportamento do canal através de tons pilotos.

\subsubsection{IQ Demapper}

No bloco IQ Demapper é realizado o processo inverso do bloco IQ Mapper. O sinal recebido é transformado em uma sequência de inteiros para comparação com o sinal transmitido, possibilitando a avaliação do desempenho do modelo. 


\subsection{Método proposto para Correção de Distorções na Resposta em Frequência do Canal}

Como o canal pode sofrer distorções devido a presença de ruído faz-se necessário a utilização de um esquema destes efeitos indesejáveis. No esquema gerado através do Simulink utilizou-se a técnica dos tons pilotos para treinar o receptor a respeito das condições do canal.

A sequência com a disposição dos tons pilotos está ilustrada na Figura 17.

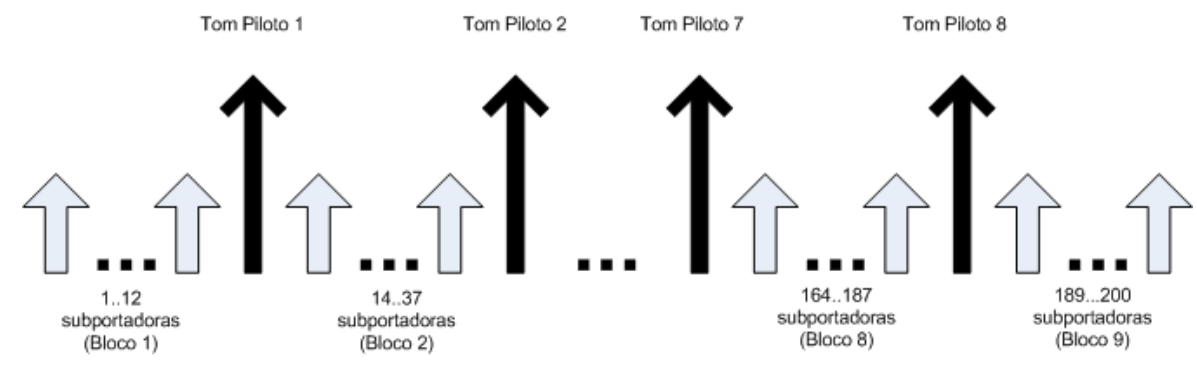

Figura 17: Tons pilotos

O método de interpolação flat foi utilizado para estimação da distorção do canal. Assumiu-se que a razão entre o tom piloto enviado pelo transmissor e o recebido é a distorção que observaremos nas subportadoras ao redor do tom piloto.

Para cada bloco utilizou-se a estimativa do canal (razão entre sinal transmitido e recebido) proveniente do tom piloto anterior ao mesmo para normalizá-lo. Para correção das subportadoras do primeiro bloco aplicou-se a estimativa da distorção do canal originada com o primeiro tom piloto.

O valor de cada um dos tons pilotos é descrito na tabela abaixo:

\begin{tabular}{|c|c|c|c|c|c|c|c|c|}
\hline Tom Piloto & 1 & 2 & 3 & 4 & 5 & 6 & 7 & 8 \\
\hline Amplitude do Sinal & 1 & -1 & 1 & -1 & 1 & 1 & 1 & 1 \\
\hline
\end{tabular}

Tabela 6: Amplitude do Sinal dos Tons Pilotos 
A Figura 18 apresenta o bloco gerado no Simulink para estimação do canal através de tons pilotos.

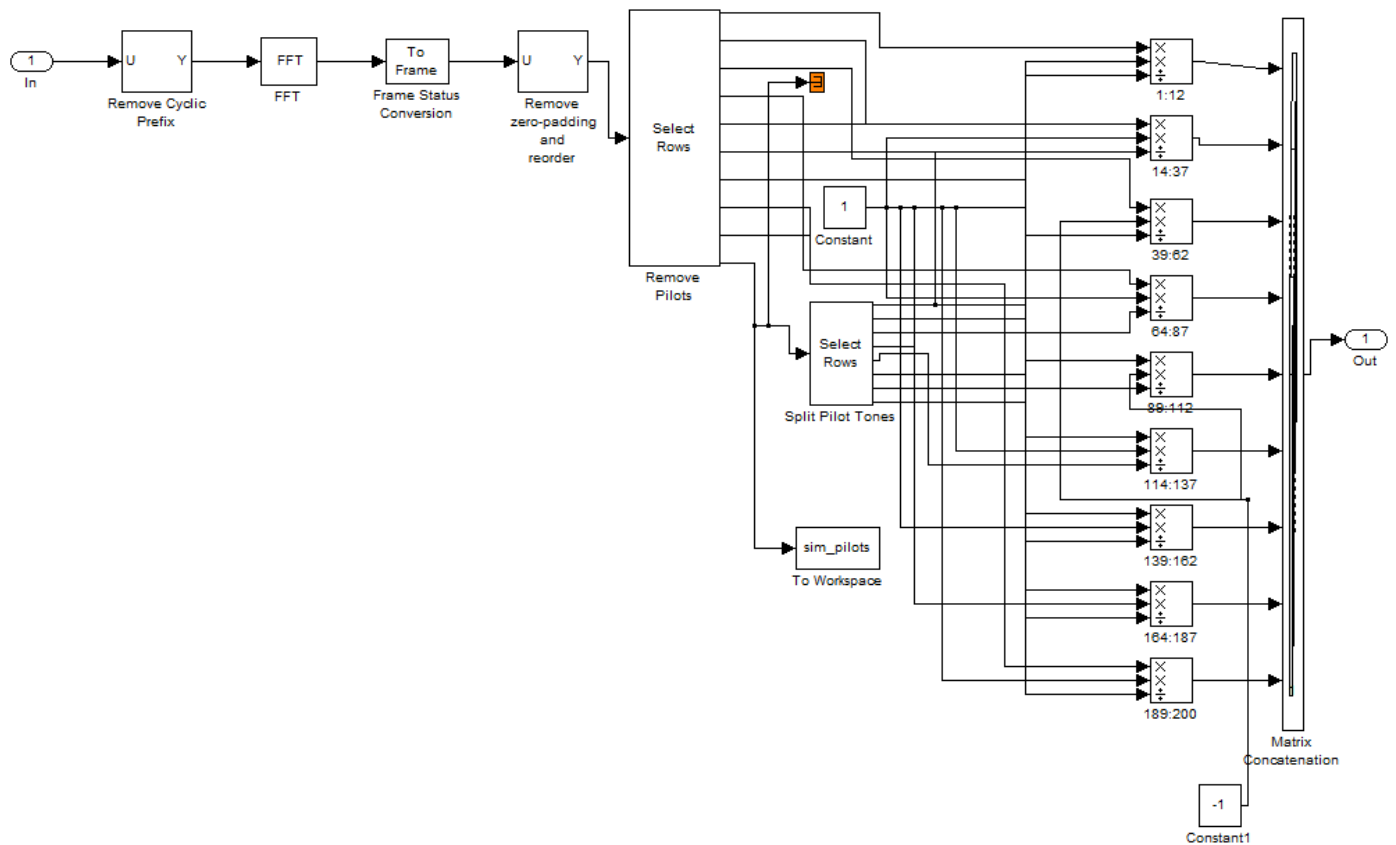

Figura 18: Bloco de Correção de Distorções no Canal através de Tons Pilotos

Na seção subjacente será avaliado o aumento de desempenho (melhora da taxa de perda de bits) devido a este método através de uma Simulação de Monte Carlo para determinados tipos de canais.

\subsection{Simulação de Monte Carlo para encontrar Desempenho do}

\section{Link}

A Figura 19 apresenta a probabilidade de perda de bits (BER) para os tipos de modulação 4-QAM, 16-QAM e 64-QAM. O objetivo desta simulação foi comparar a eficácia do método proposto para estimação do comportamento do canal através dos tons pilotos. O primeiro ponto de cada uma das três curvas se refere a estimação da probabilidade de perda de bits com o método proposto e o segundo se refere a uma abordadem simples que não estima o canal de comunicação. 
O método proposto apresentou desempenho superior à abordagem sem estimação de canal em todos os três tipos de modulação QAM considerados. Apesar de o canal ter sido estimado com uma interpolação flat nos tons pilotos que é muito simples, o método proposto se demonstrou bem eficiente.

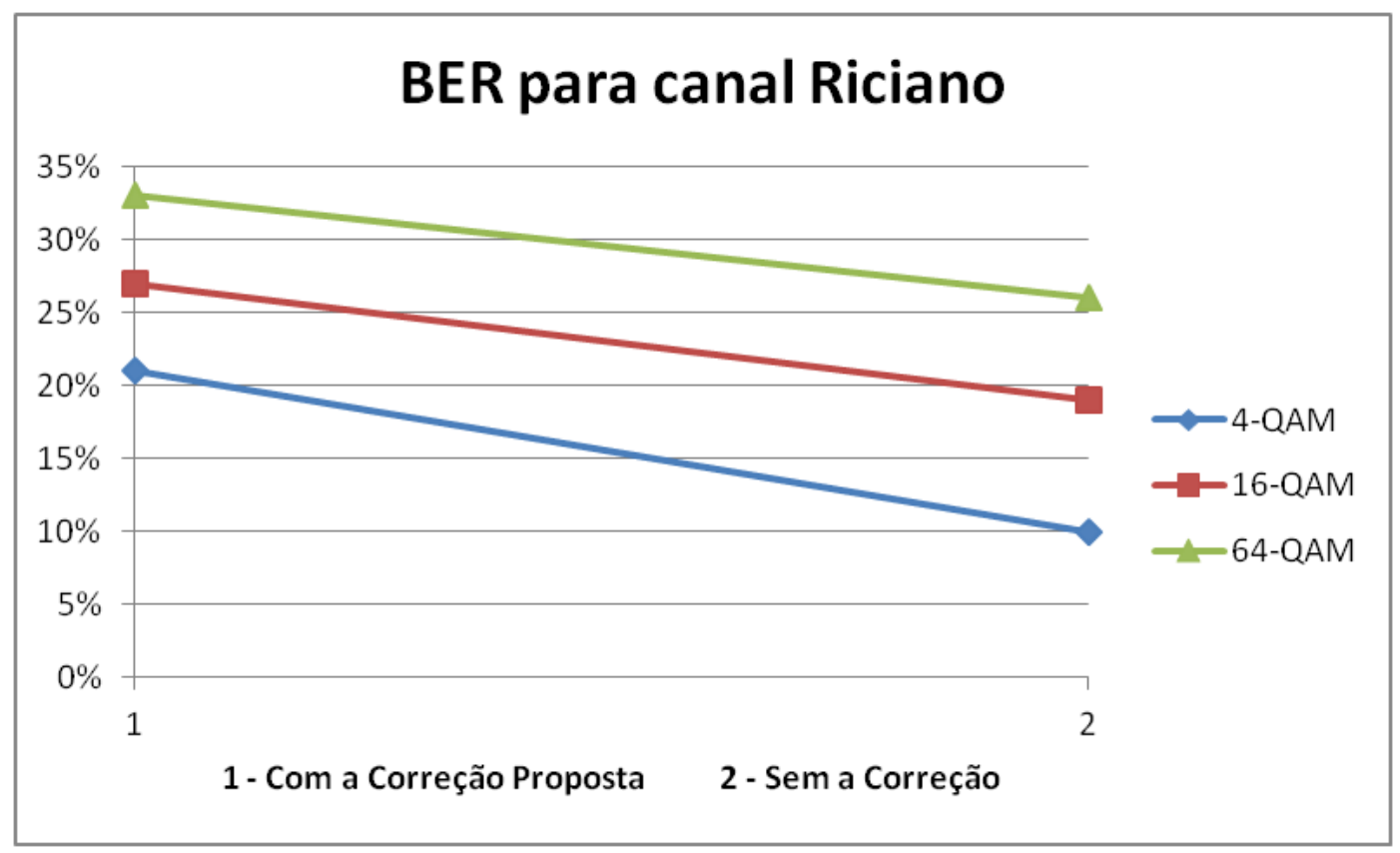

Figura 19: Bit Error Rate para canal Riciano

A Figura 20 apresenta a probabilidade de perda de bits (BER) para os tipos de modulação 4-QAM, 16-QAM e 64-QAM para os níveis de Relação Sinal-Ruído de 3, 10,30 e $50 \mathrm{dBs}$.

Os resultados das Figuras 19 e 20 ilustram o fato de que quanto mais densa a constelação utilizada da modulação QAM, maior será a perda de bits. Vale ressaltar que esta conclusão só é válida quando as constelações são normalizadas para deixá-las com a mesma energia.

O compromisso entre vazão (throughput) e perda de bits (BER), também, é ilustrado nestes resultados. Para aumentar a vazão sem aumentar a largura de banda utilizada (faixa do espectro eletromagnético) é necessário utilizar uma modulação QAM com o $M$ grande, no entanto, a detecção destes simbolos será dificultada e o receptor perderá mais 


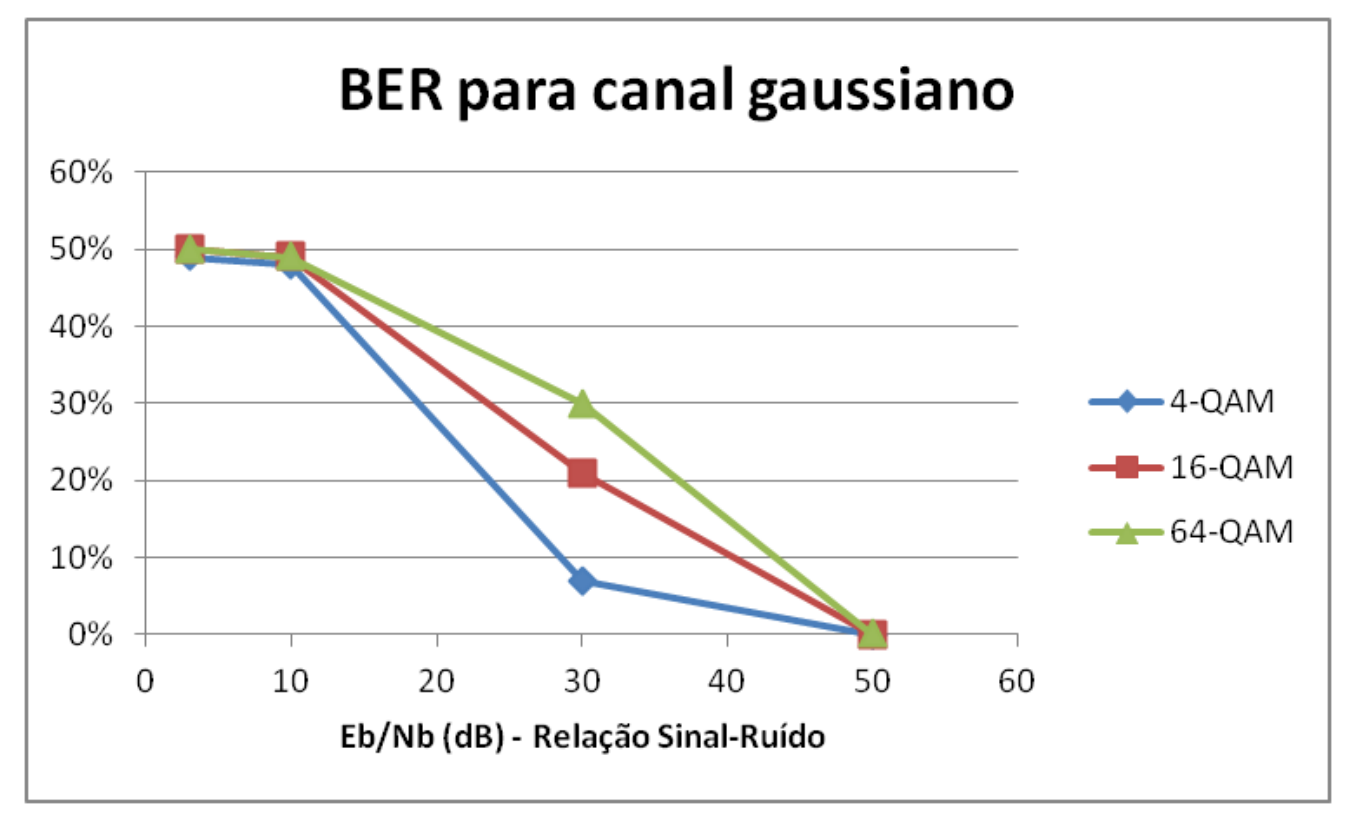

Figura 20: Bit Error Rate para canal Gaussiano

bits. Por esta razão, os modens WiFi alternam o tipo de modulação QAM utilizada dinamicamente com as alterações do meio, ou locomoção da estação móvel. Certas vezes, a única forma de estabelecer comunicação será através do tipo mais simples de modulação com o pior throughput.

\subsection{Link Budget}

Nesta seção será discutido o procedimento de Link Budget para determinação da influência dos efeitos determinísticos, no caso atenuação, que afetaram o design do enlace.

Será determinada a atenuação mínima através de um modelo simples que considera um sinal transmitido entre o transmissor e receptor, ambos fixados, em linha de visada. A potência do transmissor, $P_{t}$ e o limiar de sensibilidade do receptor, $P_{r}^{*}$, são, respectivamente, $26 \mathrm{dBm}$ e $-80 \mathrm{dBm}$. $26 \mathrm{dBm}$ equivale a potência de $500 \mathrm{~mW}$ e $-80 \mathrm{dBm}$ equivale a $10^{-8} \mathrm{~mW}$. A potência e o nível de sensibilidade utilizados referem-se a um transceptor de uma placa Wi-Fi comum. Será considerada a atenuação nos cabos e conectores de $3 \mathrm{~dB}, a_{l}$. 
Considerando a equação da atenuação de uma onda eletromagnética no espaço livre, os ganhos obtidos através da utilização de antenas, a atenuação nos cabos e conectores e a potência transmitida obtem-se a seguinte expressão para o nível de potência no receptor,

$$
P_{r}=P_{t}+G_{t}+G_{r}-a_{0}(d, f)-a_{l}
$$

onde $P_{t}$ e $P_{r}$ estão em dBm, $G_{t}, G_{r}, a_{0}$ e $a_{l}$ estão em dB. Para garantir a transmissão basta satisfazermos a condição

$$
P_{r}^{*} \geq P_{r}
$$

VANTs possuem restrições de carga e aerodinâmica. Por esta razão, não é possível equipá-los com qualquer tipo de antena, dado que peso, tamanho e formato podem impactar no desempenho destes veículos. Antenas omni-direcionais, como as do tipo monopolo, são leves e não interferem na aerodinâmica, no entanto, apresentam a desvantagem de não possuirem ganhos satisfatórios. Antenas parabólicas possuem maior ganho, porém, têm como desvantagem as dimensões. Nesta seção será avaliado a viabilidade da utilização de parabólicas de dimensões idênticas no transmissor e receptor.

O ganho de antenas parabólicas é uma função de seu diâmetro, $D$, da frequência de operação, $f$, e do índice de eficiência, $\eta$. A expressão para o ganho, $G$, (em dB) é

$$
G=10 \log \left(\eta \frac{\pi^{2} D^{2} f^{2}}{c^{2}}\right)
$$

onde $\pi \approx 3.1416$ e $c=3.10^{8} \mathrm{~m} / \mathrm{s}$ é a velocidade da luz.

Considerando que o enlace deve ficar operante em distâncias de até 100Km, o diâmetro mínimo de cada antena, de modo a manter o funcionamento do transceptor, em função da frequência de operação é 


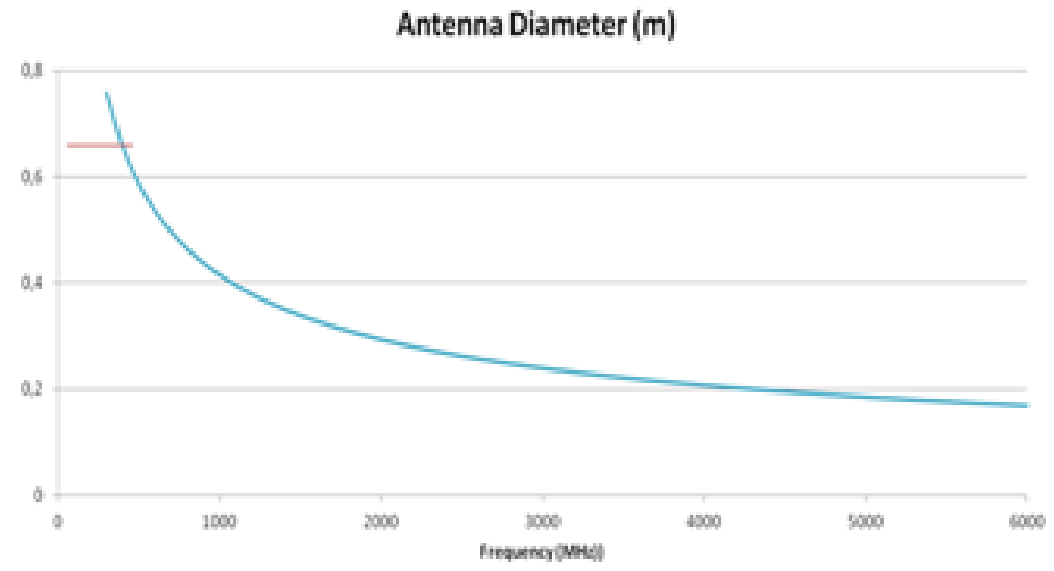

Figura 21: Diâmetro da antena em função da frequência de operação

$$
D=\frac{c}{\pi f} \sqrt{10^{\frac{a_{0}(f)+a_{l}-P_{t}+P_{r}}{40}}} .
$$

A Figura 21 apresenta o gráfico com o diâmetro de cada uma das antenas em função da frequência de operação. Para a frequência de $2.4 \mathrm{GHz}$ cada antena deve possuir no mínimo $33.5 \mathrm{~cm}$ para o enlace operar devidamente. A escolha de antenas com diâmetro reduzido é adequada para que não exista interferências aerodinâmicas no VANT.

Vale ressaltar que o índice de eficiência da antena, $\eta$, foi considerada como 1.0 para simplicidade dos cálculos. 


\section{Conclusão e Trabalhos Futuros}

O presente trabalho abordou o design do enlace de comunicação. Conforme ilustrado na Figura 13 dividimos o projeto pelo conjunto de blocos analógicos e digitais, sendo este último o que ganhou maior ênfase no projeto.

Na Seção com o Link Budget abordaram-se as questões pertinentes ao projeto dos blocos analógicos. Apresentou-se um procedimento que guiará a escolha destes itens de hardware, e, especialmente, as dimensões das antenas. Instanciou-se um caso extremamente prático para nossa análise. A potência transmitida pelo transmissor neste exemplo é o máximo permitido pela Anatel para aquela frequência e a sensibilidade do aparelho ao sinal recebido, $P_{r}$, foi de um valor usual a este tipo de equipamento.

Naturalmente, há a possibilidade de aumentar o alcance utilizando amplificadores de rádio-frequência. No entanto, isto acarretaria outros problemas, porque é necessário a permissão da Anatel para operar em frequências habilitadas para transmissão com elevadas potências.

O gráfico com o diâmetro das parabólicas, também, revela outro trade-off importante. Transmitir em frequências elevadas utilizando antenas direcionais pequenas exige um sistema mecânico que altere constantemente a posição e a inclinação das antenas para que se mantenha a linha de visada. Pode-se utilizar GPSs e acelerômetros para realização desta tarefa, no entanto, em situações adversas o enlace pode ficar completamente inoperante e as informações de localização não poderão ser transmitidas entre os nós (estação base e estação móvel). Uma solução seria a utilização de sistemas de posicionamento de antenas mais sofisticados que utilizam uma abordagem similar a dos radares. Outro fator decisivo para escolha das antenas será a restrição de tamanho e carga de cada VANT.

A parte digital do circuito foi tratada com o auxílio da ferramenta Matlab/Simulink. Um método para correção das perdas geradas por distorções no canal foi proposto baseado nos tons pilotos. O desempenho desta solução foi determinado para três tipos 
de modulação QAM.

O projeto de um enlace para um VANT real, com dimensões e principais restrições estabelecidas, seria um possível trabalho futuro. Este trabalho poderia se concentrar na construção de um protótipo em hardware com os blocos analógicos da Figura 13. A parte digital poderia ser feita de forma direta convertendo os blocos lógicos gerados no Simulink para código VHDL de FPGAs. 


\section{Referências}

[1] Em: <http:www.af.mil>. Acesso em: 8 de Julho 2012.

[2] Akyildiz I. F., Wang, X., Wang, W. Wireless mesh networks: a survey (March 2005). Computer Networks and ISDN Systems. Vol 4, Issue 4.

[3] Burow, R., Pogrzeba, P., Christ, P. Mobile Reception of DVB-T. Deutsche Telekom Berkom.

[4] Biglieri, E. MIMO Wireless Communications (2007). Cambridge University Press, New York.

[5] Dennison, M. Radio Communication Handbook (2005). Radio Society of Great Britain.

[6] Fischer, W. Digital Video and Audio Broadcasting Technology: A Practical Engineering Guide (2008). Springer-Verlag, Berlin.

[7] Forman, G. H., Zahorjan, J. The Challenges of Mobile Computing. IEEE Computer Society Press. Los Alamitos, CA. (April 1994). Vol. 27, Issue 4.

[8] Hata, M. Empirical formula for propagation loss in land mobile radio services. IEEE Transactions on Vehicular Technology, 1980.

[9] Ivancic, W. Modular, Cost-Effective, Extensible Avionics Architecture for Secure, Mobile Communications (July, 2006). In Aerospace Conference, 2006 IEEE.

[10] Khedr, M., Karmouch, A. ACAN Ad Hoc Context Aware Network. IEEE CCECE’02 (2002).

[11] Lathi, B P. Sistemas de Comunicação (1987). Guanabara, Rio de Janeiro.

[12] Liu, Y., Contractor, K., and Kang, Y. Path Loss For Short Range Telemetry. In: 4th International Workshop on Wearable and Implantable Body Sensor Networks, vol. 13, pp 70-74, March 26-28, RWTH Aachen University, German, 2007.

[13] Mateus, G. R., Loureiro, A. A. F. Introdução à Computação Móvel. Universidade Federal de Minas Gerais, 2009 .

[14] Mahmood, S. Unmaned Aerial Vehicle (UAV) Communications (2007). (Masther Thesis) Institute for Telecommunications Research, University of South Australia, Australia.

[15] Moreira, E. S., Lopes, R. R. F., Kimura, B. Y. L., Yokoyama, R. S. Uma Abordagem Ciente de Contexto para Handovers orientados a Serviços em ambientes NGN. In 7th International Information and Telecommunication Technologies Symposium (I2TS'2008), 2008, Foz do Iguaçu.

[16] Neris, L. O. Um piloto automático para aeronaves do projeto ARARA. (2001). Dissertação (Mestrado) Instituto de Ciências Matemáticas e da Computação, Universidade de São Paulo, São Carlos. 
[17] Nussenzveig, H. M. Curso de Física Básica 2 - Fluídos, Oscilações e Ondas de Calor. 4a Edicao. Editora Blucher. 2002.

[18] Em: <http:www.mathworks.commatlabcentralfileexchange16642-ofdm-with-qpsk>. Acesso em: 10 Julho 2011.

[19] Okumura, Y., et al. Field strengh and its variability in VHF and UHF land-mobile radio service. Rev. Elec. Commun. Lab, 1968.

[20] Pereira, F., Ebrahimi, T. The MPEG-4 Book (2002). Pearson.

[21] Rappaport, T. Introduction to Wireless Communication Systems. Prentice Hall, Upper Saddle River. 2001.

[22] Schmidt, D. Model-Driven Engineering (2006). IEEE Computer, 39(2), February 2006.

[23] Schuster, T.; Verma, D. Networking Concepts Comparison for Avionics Architecture. In Proceedings of the Digital Avionics Systems Conference (October, 2008).

[24] SOHAND. Disponivel em: http://sohand.icmc.usp.br. (2009, Março).

[25] Souza, N. P. Sistemas Alternativos para a Obtenção de Imagem Aérea e sua Aplicação na Agricultura. 1999. Dissertação (Mestrado) Instituto de Ciências Matemáticas e da Computação, Universidade de São Paulo, São Carlos.

[26] VLC. (2009, Março) Disponível em: http://www.videolan.org

[27] Gu, Q. RF System Design of Transceivers for Wireless Communications.

[28] Tsai, Pei-Yun et al. OFDM Baseband Receiver Design for Wireless Communications. Editora Wiley. 2007.

[29] Yang, W. Y. MIMO-OFDM Wireless Communications with MATLAB. Editora Wiley. 2010.

[30] Zhan, P. et al. Wireless Relay Communications with Unmanned Aerial Vehicles: Performance and Optmization. Disponivel em: http://newport.eecs.uci.edu/swindle/pubs/WirelessRelayCommunications.pdf 
Apêndice A - Trabalho Publicado em Evento Internacional 


\section{A Context-aware Communication Link for Unmanned Aerial Vehicles}

\author{
Edson dos Santos Moreira, Renata M. Porto \\ Vanni, Diego L. Função \\ Instituto de Ciências Matemáticas e de Computação \\ Universidade de São Paulo - USP \\ São Carlos-SP, Brazil \\ e-mail: \{edson, rporto, diego\}@icmc.usp.br
}

\author{
Cesar Augusto Cavalheiro Marcondes \\ Departamento de Computação \\ Universidade Federal de São Carlos - UFSCar \\ São Carlos-SP, Brazil \\ e-mail: marcondes@dc.ufscar.br
}

\begin{abstract}
The impact of contextual events for the performance of high bandwidth communication UAV link is the theme of this paper. Applications in this field have some strict quality requirements, and the communication link performance is essential for the mission success. Several events in the flight or in the surroundings can interfere with the data stream. We describe a context-controlled system which could dynamically adapt the flight in order to cope with eventualities during a mission. The main constraints of the link are discussed, and we analyze the link budget for the link considering directional receiving and transmitting antennas.
\end{abstract} System.

Keywords - UAVs; Context-aware; Critical Communication

\section{INTRODUCTION}

An Unmanned Aerial Vehicle (UAV) is an autonomous flying vehicle controlled by its' embedded system. Their main uses are in the field of military applications, but other uses, such airspace surveillance and environmental monitoring operations are increasing. Figure 1 illustrates a scenario where UAVs are part of a squadron mission and work in a collaborative manner. A mission is a preestablished set of maneuvers that an UAV is due to execute in the task of pursuing a target. Usually, the mission is composed by a route (which specifies the geographical path to be flown by the UAV and its altitude), a timeline (showing possible timing requirements for the task), and a sensor control table (that stores the list of actions that the sensors must perform in order to acquire the necessary data for the task). The sensor control table is linked to the route and the timeline. Eventually the actions can be changed onthe-flight by the ground control station or in few cases autonomously. Depending on the UAV capabilities and the characteristics of the mission, a route can be preemptive (the route can be changed to meet an unexpected event during the flight) or non-preemptive (the route cannot be changed).

A ground control station is a terrestrial base instrumented in such a way that basic flight management, sensor control and monitoring are performed. The communication to the UAV can be performed in several ways. Usually, a well equipped system will have a GPS antenna, to get the proper geographical positioning and timing; an additional GPS radio link to a reference nearby point in order to calculate differential positioning; an omni-directional radio link with the ground control station for maneuvers in the vicinities of the station; a directional line-of-sight link to provide runtime communication between UAVs or with the ground when the UAV is distant from the ground control station. The more advanced UAVs [predator], [heron] also might have a satellite link which can extend the capabilities of device beyond the reach of the unidirectional link, in addition to provide backup.

The area to be covered by a mission can vary from small regions as farms and small cities to wide ones as the borders of extensive countries, like Brazil. For that reason, the communication link range has to be optimized for better results in unoccupied places or lacking in communication infrastructure.

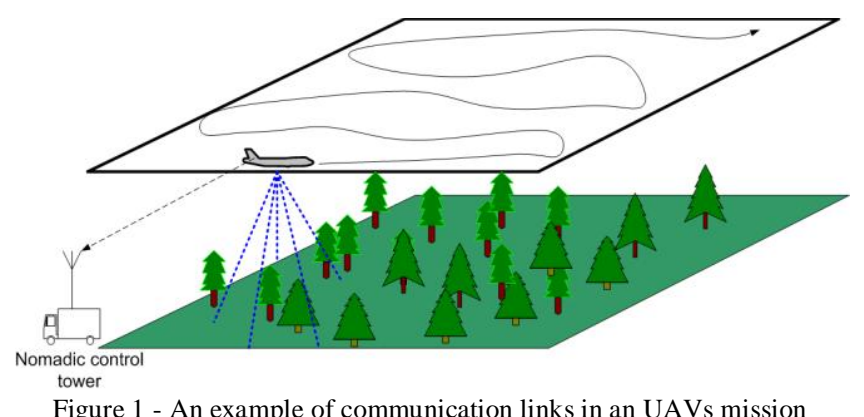

This paper deals with the specification and design of an adaptive context-aware directional radio link for UAVs. In special, we focus on the communication radio link composed of a ground control communication system, ground tower, ground antenna, a carrier RF signal which transport a coded data stream, UAV onboard antenna, and UAV onboard control communication system.

The communication link, once deployed in the field, can experience several interference sources (environment conditions, frequency of the carrier, gain of the antennas, geographical obstacles, etc) degrading the long distance capacity and the quality. Furthermore, the nature of the task and the mission constraints (fuel consumption, route, costs, etc.) can influence (i.e., changes in flight control) and/or be further influenced by the flight conditions and the link requirements. The contextual conditions in which the flight is subjected and the influence it has on the communication link are part of this study. In order to deal with the range of 
variables in a mission, it is expected that the UAV's communication link supports on-the-fly adaptation or some change based on the context alterations[10]. The awareness of the context provides the necessary knowledge to accomplish the choice of the most appropriate reparametrization of the link communication in each situation.

The rest of the paper is organized as follows: in Section II, we survey and classify the several context-type information that can lead to an improvement of the link quality, in Section III, we discuss how the UAV system interfaces with the communication link sub-system and how this data flow can change link configuration in order to cope with unexpected signal conditions. In Section IV, we deal with some design issues when considering mission restrictions of fair connectivity while maintaining high image capturing quality and we describe in more detailed terms (i.e., FPGA sub-systems, attenuation vs modulation) and conclude the positional paper in Section V.

\section{CONTEXT-AWARENESS TO IMPROVE COMMUNICATION LINK QUALITY}

Contextual parameters are crucial in our design and they are specified in Table I. These contextual parameters can be easily gathered from a number of sources, including internal and remote sensors (eventually in the ground). Other implicit measurements can be carried out directly from the communication link in use (bandwidth, signal-to-noise ratio, packet delay, BER, etc). Finally the mission context (geography, duration, fuel consumption, etc) will impose a number of restrictions. In this way contextual parameters can create the ground bases for the adaptation of the UAV communication link.

Table I shows a thorough list of contexts that could trigger adaptation of the communication link. In the table, our goal is to classify the type of contexts based on signal quality, security, resourcefulness, environmental conditions, geography, navigational and critical restrictions. For every type of context, we illustrate the representative contextual parameters gathered by the sensors, or the like, in the UAV, and we describe in detail everyone of these parameters.

\section{TABLE I. CONTEXTUAL PARAMETERS}

\begin{tabular}{|c|c|c|}
\hline \multicolumn{2}{|c|}{ Contextual Parameters } \\
\hline $\begin{array}{c}\text { Type of } \\
\text { Context }\end{array}$ & $\begin{array}{c}\text { Contextual } \\
\text { parameter }\end{array}$ & Contextual parameter Description \\
\hline $\begin{array}{c}\text { Signal/link } \\
\text { quality } \\
\text { the quality of } \\
\text { the } \\
\text { electromagneti } \\
\text { c wave } \\
\text { transporting } \\
\text { data) }\end{array}$ & $\begin{array}{c}\text { Signal to noise } \\
\text { ratio (S/N) }\end{array}$ & $\begin{array}{c}\text { The ratio of a signal power to the } \\
\text { noise power corrupting the signal. A } \\
\text { ratio higher than 1:1 indicates more } \\
\text { signal than noise. }\end{array}$ \\
\cline { 2 - 3 } & Bit error ratio & $\begin{array}{c}\text { The number of erroneous bits } \\
\text { (BER) } \\
\text { received divided by the total number } \\
\text { of bits transmitted during a specified } \\
\text { time interval. }\end{array}$ \\
\cline { 2 - 3 } & Bandwidth & $\begin{array}{c}\text { The available data communication } \\
\text { resources expressed in bit/s }\end{array}$ \\
\hline
\end{tabular}

\begin{tabular}{|c|c|c|}
\hline \multicolumn{3}{|c|}{ Contextual Parameters } \\
\hline \multirow[t]{4}{*}{$\begin{array}{l}\text { Type of } \\
\text { Context }\end{array}$} & $\begin{array}{l}\text { Contextual } \\
\text { parameter }\end{array}$ & Contextual parameter Description \\
\hline & Delay (latency) & $\begin{array}{l}\text { The time required for a data packet } \\
\text { to travel from a specific source to a } \\
\text { specific destination and back again. }\end{array}$ \\
\hline & Jitter & $\begin{array}{l}\text { The measure of the variability over } \\
\text { time of the data packet latency across } \\
\text { the link. A link communication with } \\
\text { constant latency has no variation (no } \\
\text { jitter). }\end{array}$ \\
\hline & $\begin{array}{c}\text { Link } \\
\text { Availability }\end{array}$ & $\begin{array}{c}\text { The ratio of the expected value of the } \\
\text { uptime of the communication link } \\
\text { divided by the sum of the expected } \\
\text { values of up and expected values of } \\
\text { down time. } \\
\text { A=E(uptime)/(E(uptime)+E(downti } \\
\text { me)) }\end{array}$ \\
\hline \multirow{3}{*}{$\begin{array}{c}\text { Security } \\
\text { (Security is the } \\
\text { means of } \\
\text { ensuring that } \\
\text { data is kept } \\
\text { safe from } \\
\text { corruption and } \\
\text { that access to it } \\
\text { is suitably } \\
\text { controlled) }\end{array}$} & Integrity & $\begin{array}{l}\text { Data that has integrity is identically } \\
\text { maintained during the transfer } \\
\text { operation by the link. }\end{array}$ \\
\hline & Confidentiality & $\begin{array}{l}\text { The guarantee that the data transfer } \\
\text { into the link will not be disclosed. }\end{array}$ \\
\hline & Authenticity & $\begin{array}{c}\text { The use of some technology to prove } \\
\text { the data is authentic, i.e. generated } \\
\text { by an authorized source. }\end{array}$ \\
\hline \multirow{3}{*}{$\begin{array}{l}\text { Resource } \\
\text { (the amount of } \\
\text { available } \\
\text { resources to the } \\
\text { UAV mission) }\end{array}$} & $\begin{array}{c}\text { Energy } \\
\text { consumption }\end{array}$ & $\begin{array}{l}\text { The energy consumption in terms of } \\
\text { battery power for data transmission } \\
\text { and data reception. }\end{array}$ \\
\hline & Fuel & $\begin{array}{l}\text { The amount of gas in the aircraft, } \\
\text { specifies the range of coverage }\end{array}$ \\
\hline & Mission budget & $\begin{array}{l}\text { The total sum of money set aside for } \\
\text { a mission. This information is } \\
\text { necessary when the link utilization is } \\
\text { charged. }\end{array}$ \\
\hline \multirow[t]{5}{*}{ Environment } & $\begin{array}{l}\text { Temperature } \\
\text { Rain } \\
\text { Cloudiness } \\
\text { Moisture } \\
\text { Pressure }\end{array}$ & $\begin{array}{l}\text { The state of the atmosphere with } \\
\text { respect to elements that can interferer } \\
\text { with the data transmission, as wind, } \\
\text { temperature, cloudiness, moisture } \\
\text { and pressure. Related to weather, but } \\
\text { the amount of water determines } \\
\text { signal degradation by absorption of } \\
\text { electromagnetic radiation. }\end{array}$ \\
\hline & Flying animals & $\begin{array}{l}\text { The presence of this sort of animals } \\
\text { should damage the UAV. }\end{array}$ \\
\hline & Smoke & $\begin{array}{l}\text { Smoke can cause image definition } \\
\text { degradation and UAV instability. }\end{array}$ \\
\hline & Pollution & $\begin{array}{c}\text { Pollution can cause image definition } \\
\text { degradation and damage to the } \\
\text { equipments. }\end{array}$ \\
\hline & Wind & $\begin{array}{l}\text { Related to the weather, but some } \\
\text { aerial maneuver can deal with it. }\end{array}$ \\
\hline \multirow[t]{3}{*}{ Geography } & $\begin{array}{l}\text { Natural features } \\
\text { (hill, mountain) }\end{array}$ & $\begin{array}{l}\text { The presence of geographical } \\
\text { obstacle must be detected } \\
\text { beforehand, but the interference of } \\
\text { them on signal quality sometimes } \\
\text { cannot be predicted. }\end{array}$ \\
\hline & Obstacles & Building, tower, etc. \\
\hline & Land occupation & $\begin{array}{l}\text { urban or rural area, crops, river, } \\
\text { swamp, desert, etc... }\end{array}$ \\
\hline \multirow[t]{2}{*}{ Navegability } & Plane rolling & $\begin{array}{l}\text { Rotational movement of the UAV } \\
\text { around its longitudinal axis. }\end{array}$ \\
\hline & line of sight & a straight line connecting two points \\
\hline
\end{tabular}




\begin{tabular}{|c|c|c|}
\hline \multicolumn{3}{|c|}{ Contextual Parameters } \\
\hline $\begin{array}{c}\text { Type of } \\
\text { Context }\end{array}$ & $\begin{array}{c}\text { Contextual } \\
\text { parameter }\end{array}$ & Contextual parameter Description \\
\hline & Route & air flight mission planning \\
\hline $\begin{array}{c}\text { Mission } \\
\text { criticality }\end{array}$ & Several & $\begin{array}{c}\text { Several critical aspects that could be } \\
\text { incorporated in the mission }\end{array}$ \\
\hline
\end{tabular}

Whenever deployed in the field, we combine some of this contextual information we may have to deal with drastic adversities in the radio communication link. Figure 2 shows the architecture to gather this information and manage it in order to support communication link adaptation.

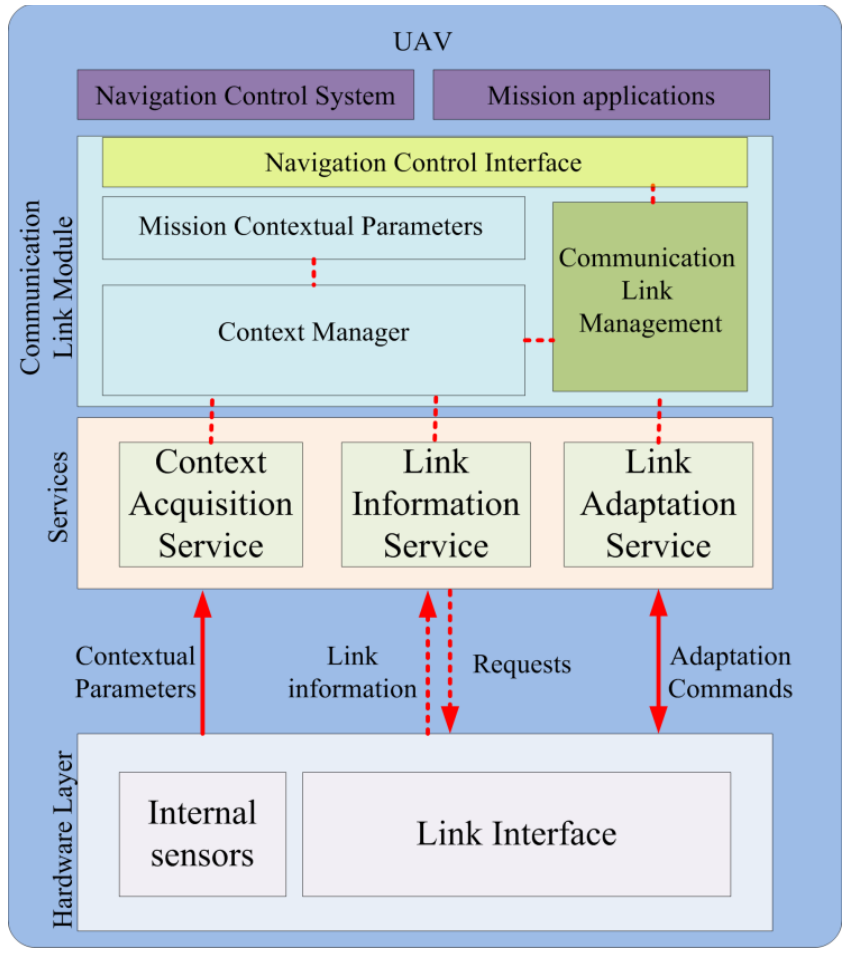

Figure 2 - Context-awareness architecture in UAV

The architecture is composed by three services (Context Acquisition Service, Link Information Service, and Link Adaptation Service) that gather information from the Hardware Layer to the Communication Link Module, and trigger commands to adapt the communication link. The set of information includes contextual parameters, link information requests and responses, and adaptation commands. The Context Manager updates the types of context using the Mission Contextual Parameters, and contextual parameters gathered from the Context Acquisition Service and from the Link Information Service. The Communication Link Management decides for a specific adaptation action based on a set of rules using the contexts provided by the Context Manager. For example, consider the link strength diminishing while the aircraft is rolling due to the mission restriction of maintaining connectivity at all costs. This may trigger many types of adaptation commands from the Communication Link Management using the Link
Adaptation Service, such as change of the modulation (BPSK instead of a 64-QAM) in order to cope with a increasingly bad link, or even in some drastic cases with changes to the frequency been used, as one would do using 802.11 and all the compatible versions $(\mathrm{a} / \mathrm{b} / \mathrm{g})$ embedded in the single system. Finally, the Navigation Control Interface provides to the Navigation Control System and to other mission applications the critical information so to comply with the link conditions.

In this way, the contextual information will interfere with UAV overall control and with the embedded applications in order to keep the communication necessities of the mission.

\section{INTERFACING WITH THE UAV}

In this section, we describe one UAV architecture which presents a block diagram representing a typical UAV hardware architecture [1]. The architecture uses four processors in a unique embedded board.

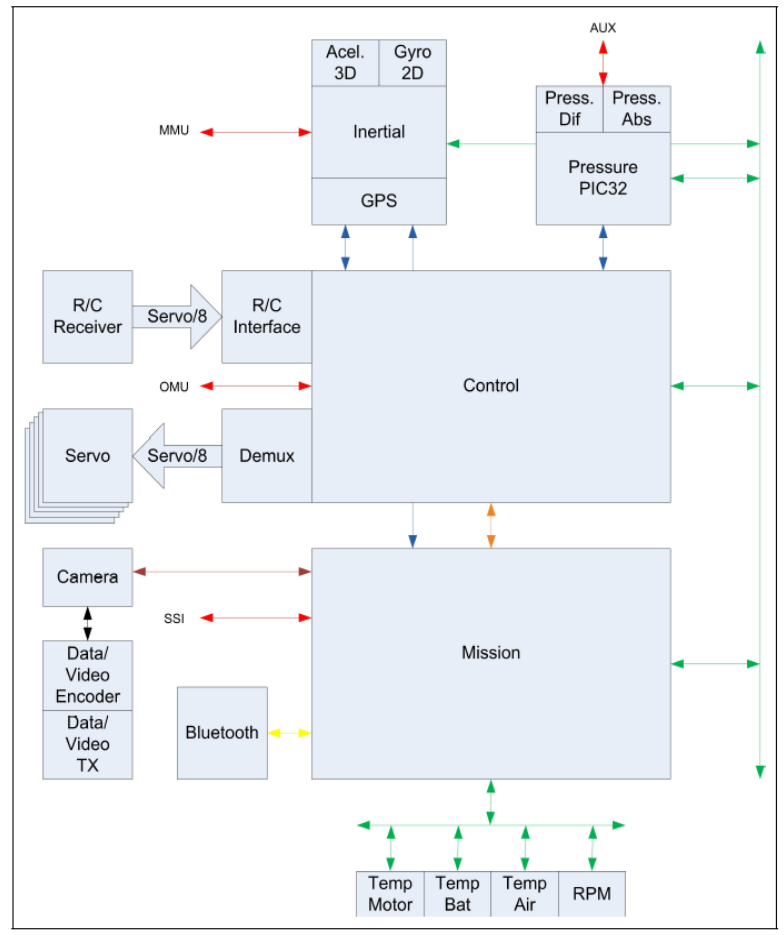

Figure 3 - UAV Overall System

The first processor (also called Mission) is responsible for the mission accomplishment, i.e., the execution of the previously planned tasks. The second processor (also called Control) is responsible for the UAV navigability. It receives basic pilot-like commands from the mission processor and from the control tower. Finally, the last two processors implement the processing stream of two main sets of flight sensors: (a) the inertial unit integrating a GPS receptor and a module for terrestrial magnetic field measurement (this one responsible to determine the UAV altitude), and (b) a barometric unit to measure the aerodynamic velocity, 
barometric altitude and the UAV ascension rate [1]. All these subsystem can be connected to the Navigation Control Interface (see Figure 2) in order to response to the actions suggested by the Link Communication Management Module.

\section{DESIGN ISSUES FROM THE COMMUNICATION LINK}

In this session, we describe some of the design issues related to the utilization of context aware data and the tradeoffs of designing an adaptive UAV link. In particular, we describe in $A$, an equation-based scheme to recalibrate or dynamically change the gain of the antenna depending on the attenuation conditions. Afterwards, we describe technique to cope with lack of line-of-sight (LOS) in $B$, the use of adaptive modulation scheme is described in $C$. We finish the design decisions describing how to cope with multi-path fading in $D$, maximize throughput exploring spatial diversity through multiple antennas in $E$ and some preliminary diagram of the implementation of the design in $F$.

\section{A. Attenuation Design}

The easiest approach in wireless communication link design is to utilize a fixed signal strength in the transmitter that guarantees the communication over the pre-determined range compensating for a certain fading margin, through calculations of the attenuation levels. The attenuation in free space, also called free-space loss, of an electromagnetic wave is a function of the propagated distance, $d$, and the frequency, f. The total attenuation in $\mathrm{dB}$ [7] can be calculated through the following equation (1). In this, the measurement units of $\mathrm{d}$ and $\mathrm{f}$ are kilometers and megahertz respectively and $\mathrm{c}=32.45 \mathrm{~dB}$ :

$$
a_{0}(d, f)=20 \log (d)+20 \log (f)+c
$$

Applying the attenuation in free-space, $\mathrm{a}_{0}$, and the attenuation inside wires and connectors called $\mathrm{a}_{\mathrm{r}}$, and also the threshold signal from the reception, $\mathrm{P}_{\mathrm{r}}(\mathrm{dBm})$, we can easily estimate the minimum signal strength we will need in the UAV transmitter [8], $\mathrm{P}_{\mathrm{t}}(\mathrm{dBm})$, according to equation (2). The parameters $G_{t}$ and $G_{r}$ are the respective antenna gains utilized in the transmitter and receptor, respectively.

$$
P_{t}=P_{r}+a_{0}+a_{r}-G_{f}-G_{r}
$$

The communication equipment installed in the UAVs is likely to have restriction of size and weight, for this reason, we anticipate that UAVs may have to be build using small antennas. The most "off-the-shelf" solution in this case employs omni-directional antennas (or the monopole type), despite of that, we might want to increase the range covered using components to turn the antenna into directional ones with high gain (Parabolic-like).

\section{B. Coping with Lack of Line of Sight (LOS)}

In a recent work, Nakamura et al. have discussed a control technique that exploits the redundancy of robots arm joints in order to predict movements [2]. Gans et al. [4] then applied such concepts to solve the problem of surveillance of a large area through UAVs equipped with video cameras while at same time managing to guarantee the connectivity at all times. by making the UAVs close to each other, in a control theoretic coordinated fashion. However, their approach do not take into account the restrictions imposed by directional link that could be violated due to VANTs fast movement or by natural obstacles (such as mountains or large trees). A more realistic approach would use in addition the LOS and the distance to further maintain the connectivity, and this would need a pro-active controller of the link, that has to be able to detour smoothly the preestablished trajectory in the mission to a new route in order to guarantee connectivity.

\section{Exploiting Multibit Modulation}

The wireless standards 802.11 and 802.16 were designed to exploit some degree of contextual information to solve issues of weak signal, availability and packet loss. In these standards, there is a constantly monitoring daemon measuring the signal-noise ratio (SNR) in order to alternate the modulation technique to be used among several types BPSK, QPSK, 16-QAM e 64-QAM. Whenever the SNR is high (signal strong compared to noise), the system uses the modulation that generates more bits per symbol (i.e. 16QAM and 64-QAM), and, on the other hand, whenever the SNR is low it is used a modulation that presents a low bit error probability (more robust to interference and fading) such as QPSK and BPSK). In our architecture the Communication Link Management alternate modulation scheme when SNR change.

\section{Copying with Multi-Path Fading}

Typically, UAVs are engaged in missions to recognize, patrol, explore, monitor large areas of land. These conditions could turn the link subject to interference by natural phenomena that can degrade the transmission performance. In particular, for long range UAV communication, we could experience multipath fading effects (the most significant) and long delays.

The multipath problem can be solved in the UAV through a transmission technique that resembles Orthogonal Frequency Division Multiplexing (OFDM). By dividing the available spectrum band, $\mathrm{B}$, in $\mathrm{N}$ subcarriers, we reduce drastically the effect. In fact, as much more sub-carries one has, less effect it will experience, however, there is a cost in terms of complexity of the hardware and susceptibility to the Doppler Effect. 802.11 and 802.16 use OFDM to solve multipath propagation problems.

The Doppler Effect happens in UAVs that are approaching each other at high speed. In this area, Wu et al. 
[3] investigated the variability of the SNR as a function of the relative velocities between VANTs, and Robertson and Kaiser [5] described a method to ameliorate this effect through the correction of the local oscillator frequency in order to minimize the ICI (Inter subcarrier interference). As an alternative, we could reduce slightly the number of subcarries $\mathrm{N}$ to achieve similar objective. The Communication Link Management must be able to choose appropriate number of subcarriers because it interferes in multipath effects.

\section{E. Coping with Throughput Difficulties}

One desirable goal in any communication design is to have control of the throughput from UAV to ground and vice-versa in order to send the acquired information (such as pictures or high resolution video) with the specified quality. One approach that is interesting is to exploit spatial redundancy through more than one antenna using a technique like MIMO [6]. However, since the aircraft is constrained in terms of the payload, it is more appropriate to design the multiple antenna scenario in the ground base station. According to the equation (3), the known capacity limit, given in bits/Hertz, using SIMO at the UAV and MISO at the ground base station, is calculated. In that equation $\mathrm{M}$ is the number of antennas in the ground station and $E_{s} / N_{0}$ is the signal-to-noise ratio [6].

$$
C=\log _{2}\left(1+M \frac{E_{s}}{N_{0}}\right)
$$

In conditions where the signal-to-noise ratio is degraded, the capacity will decrease, so the bandwidth must be increased to keep constant throughput.

\section{F. High-level Prototype Implementation}

Finally, we envision that it would be appropriate to give flexibility to the communication system through a implementation that uses a mixture of a sophisticated antenna circuitry combined with low powered customized FPGA designs ready for several of the radio specifications in software modules, such as modulation, filters and others. The Figure 4 presents such a design where we show only the detail of the interface to the antenna.

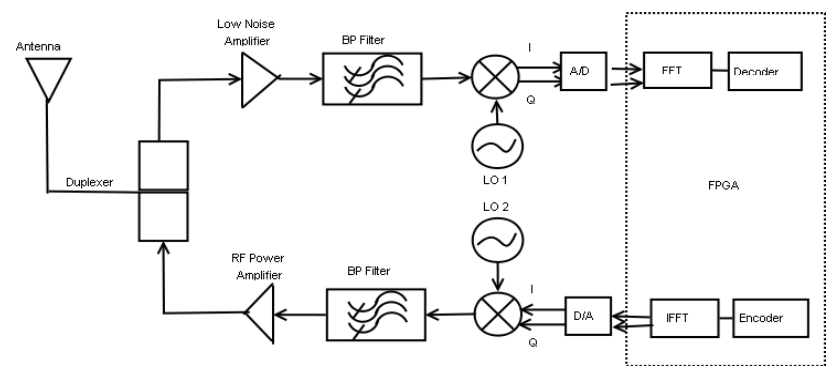

Figure 4 - FPGA to perform low-powered radio functions

\section{G. Case Study}

Let's consider a link with maximum range, $\mathrm{R}=100 \mathrm{~km}$, transmitter power, $P_{t}=26 \mathrm{dBm}$, receiver threshold, $P_{r}=-$ $80 \mathrm{dBm}$, attenuation in the line and connectors, $\mathrm{a}_{\mathrm{r}}=3 \mathrm{~dB}$. The receiver and transmitter are equipped with parabolic antennas. Figure 5 shows the attenuation for this range.

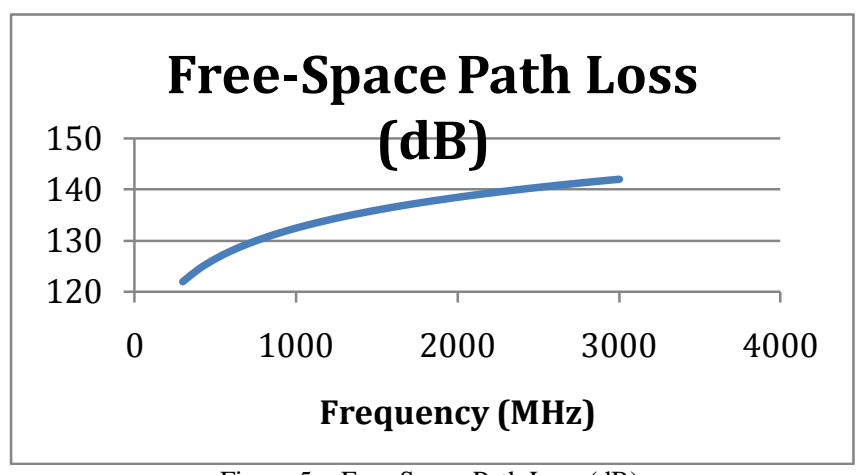

Figure 5 - Free-Space Path Loss (dB)

The gain of a parabolic antenna is

$$
G=10 \log \eta \frac{\pi^{2} D^{2} f^{2}}{c^{2}}
$$

where $\mathrm{D}$ is the parabolic diameter, $\mathrm{f}$ is the operation frequency, $c=3.10^{8}$ and $\eta$ is the efficiency of antenna [9]. For simplicity we considered $\eta=1$.

We derive a closed formula for the parabolic diameter at the radio receiver and transmitter as a function of frequency:

$$
\boldsymbol{D}=\frac{\boldsymbol{c}}{\boldsymbol{\pi} \boldsymbol{f}} \sqrt{10^{\frac{a_{0}(\boldsymbol{f})+a_{l}-\boldsymbol{P}_{t}+\boldsymbol{P}_{r}}{40}}}
$$

Figure 6 shows the diameter for each parabolic antenna. At the frequency of $2,4 \mathrm{GHz}$ we need a parabolic antenna with $33.5 \mathrm{~cm}$ of diameter. We must choose parabolic antennas with small diameter, because UAVs don't support heavy loads. Aerodynamic constraints are other reasons to this choice. 


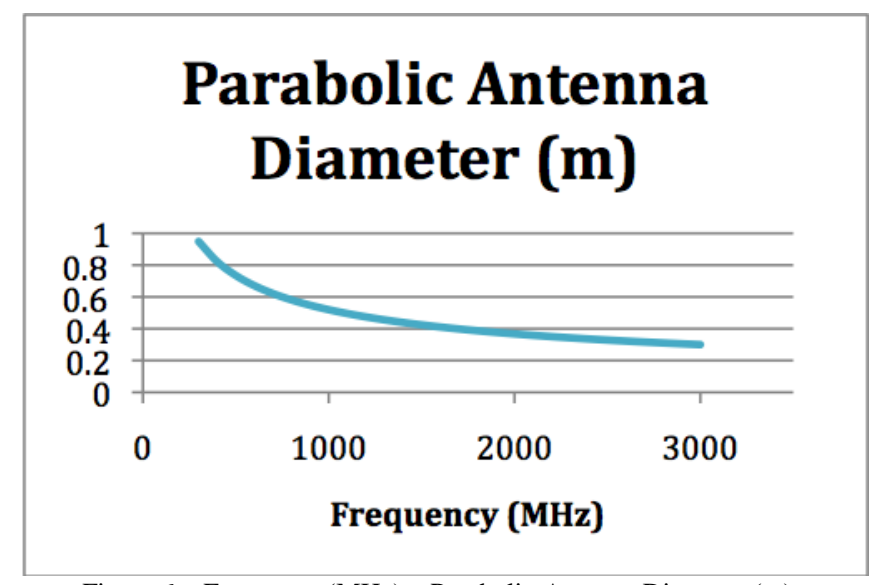

Figure 6 - Frequency (MHz) x Parabolic Antenna Diameter (m)

\section{CONCLUSIONS AND FURTHER DIRECTIONS}

In this work, we described some work done for the design of a communication link for UAVs. The design is heavily based on context-aware information to reparameterize and adapt the link in order to sustain its critical goals in a mission. The idea is coupling the UAV common subsystem and sensors to the communication link and control. In harsh conditions, the link could recover in a soft mode through changes in link-level parameters such as power, adjust gain, improving FEC and change antenna directionality while a hard mode could be drastic as to change the communication used frequencies and changing the mission planner in order to cope with aerial maneuvers that are better suited to maintain the UAV-ground connectivity. UAVs must be equipped with small antennas. We conclude that it is possible to reduce the antennas dimensions without increasing the output power or receiver sensitivity (Figure 6).

In the future, we intend to prototype our design and field experiment in collaboration with a team that developed a real UAV in Brazil within the National Science Institute for Critical Embedded Systems. We also intend to incorporate multiple antenna and handover capabilities in an urban scenario.

\section{ACKNOWLEDGMENT}

We are thankful to FAPESP and CNPq for the support to this project.

\section{REFERENCES}

[1] Trindade, O., Braga, R. T. V., Neris, L. O., and Branco, K. R. L. J. C. A Methogology to Develop Critical Embbebed Systems aiming at Certification.. In: IX Simpósio Brasileiro de Automação Inteligente, pp 1-8, 2009 (in portuguese).

[2] Nakamura, Y., Hanafusa, H., and Yoshikawa, T. Task-priority based redundancy control of robot manipulators. Int. J. Rob. Res. Journal, Vol. 6, number 2, pp 3-15, Jul. 1987.

DOI= http://dx.doi.org/10.1177/027836498700600201

[3] Wu, Z., Kumar, H., and Davari, A. Performance evaluation of OFDM transmission in UAV wireless communication. In: Thirty-Seventh Southeastern Symposium on System Theory, Southeastern Symposium on System Theory, pp. 6-10, SSST '05., 2005.

DOI: http://doi.ieeecomputersociety.org/10.1109/SSST.2005.1460867

[4] Gans, N. R., Shea, J. M., Barooah, P., and Dixon, W. E. Ensuring network connectivity of UAV's performing video reconnaissance. In: Military Communications Conference, MILCOM 2008. IEEE , pp.17, 16-19 Nov. 2008.

DOI: http://dx.doi.org/10.1109/MILCOM.2008.4753075

[5] Robertson, P. and Kaiser, S. Analysis of Doppler Spread Perturbations in OFDM(A) Systems. In: European Transactions on Telecommunications, vol. 11, number 6, pp 585-592, 2000.

DOI: http://dx.doi.org/10.1002/ett.4460110609

[6] Jankiraman, M. Space-time codes and MIMO Systems Book, 324pp, first edition, Artech House Inc. ISBN: 9781580538657.

[7] Liu, Y., Contractor, K., and Kang, Y. Path Loss For Short Range Telemetry. In: 4th International Workshop on Wearable and Implantable Body Sensor Networks, vol. 13, pp 70-74, March 26 - 28, RWTH Aachen University, German, 2007. DOI: http://dx.doi.org/10.1007/978-3-540-70994-7_12

[8] Gu, Q. RF System Design of Transceivers for Wireless Communications Book, 496pp, Springer-Verlag New York, Inc., first edition, ISBN-13: 9780387241616.

[9] Straw, R. D., Cebik, L. B., and Hallidy, D. The ARRL Antenna Book, American Radio Relay League, Newington, Connecticut, $21^{\text {st }}$ edition, 2007. ISBN: 0-87259-987-6.

[10] Schilit, B., Adams, N., and Want, R. Context-aware computing applications. In: Workshop on Mobile Computing Systems and Applications, pp.85-90, 8-9 Dec 1994.

DOI: http://dx.doi.org/10.1109/MCSA.1994.512740 